Article

\title{
Raw Material Variability and Its Impact on the Online Adaptive Control of Cohesive Powder Blend Homogeneity Using NIR Spectroscopy
}

\author{
Guolin Shi ${ }^{1}$, Bing Xu ${ }^{1,2, *}$, Zhiqiang Zhang ${ }^{2,3}$, Chan Yang ${ }^{1}$, Shengyun Dai ${ }^{1}$, Zhaozhou Lin ${ }^{2}$, \\ Xinyuan Shi ${ }^{1,2}$, Jing $\mathrm{Fu}^{2,3}$ and Yanjiang Qiao 1,2,* \\ 1 Research Center of Traditional Chinese Medicine Information Engineering, School of Chinese Materia \\ Medica, Beijing University of Chinese Medicine, Beijing 10029, China \\ 2 Beijing Key Laboratory for Production Process Control and Quality Evaluation of Traditional Chinese \\ Medicine, Beijing 100029, China \\ 3 Beijing Tcmages Pharmaceutical Co., Ltd., Beijing 101301, China \\ * Correspondence: xubing@bucm.edu.cn (B.X.); yjqiao@263.net (Y.Q.)
}

Received: 24 July 2019; Accepted: 23 August 2019; Published: 28 August 2019

check for updates

\begin{abstract}
It is significant to analyze the blend homogeneity of cohesive powders during pharmaceutical manufacturing in order to provide the exact content of the active pharmaceutical ingredient (API) for each individual dose unit. In this paper, an online monitoring platform using an MEMS near infrared (NIR) sensor was designed to control the bin blending process of cohesive powders. The state of blend homogeneity was detected by an adaptive algorithm, which was calibration free. The online control procedures and algorithm's parameters were fine-tuned through six pilot experiments and were successfully transferred to the industrial production. The reliability of homogeneity detection results was validated by 16 commercial scale experiments using 16 kinds of natural product powders (NPPs), respectively. Furthermore, 19 physical quality attributes of all NPPs and the excipient were fully characterized. The blending end time was used to denote the degree of difficulty of blending. The empirical relationships between variability of NPPs and the blending end time were captured by latent variable modeling. The critical material attributes (CMAs) affecting the blending process were identified as the particle shape and flowability descriptors of cohesive powders. Under the framework of quality by design $(\mathrm{QbD})$ and process analytical technology (PAT), the online NIR spectroscopy together with the powder characterization facilitated a deeper understanding of the mixing process.
\end{abstract}

Keywords: near-infrared sensor; blend homogeneity; cohesive powder; adaptive modeling algorithm; raw material variability; quality by design

\section{HIGHLIGHT}

$>\quad$ The near infrared (NIR) spectroscopy combined with modified adaptive algorithm was used to monitor the blending process of natural product powders and excipient systems.

$>\quad$ The effectiveness of the online monitoring platform was justified through 16 batches of commercial blending operations.

$>\quad$ An empirical relationship between raw material variability and detected blending end time were established.

$>\quad$ The particle irregularity and powder flowability were identified as critical material attributes affecting the cohesive powder blending process. 


\section{Introduction}

The powder mixing process is one of the key processes for the production of pharmaceutical oral solid preparations. Only mixed homogeneous pharmaceutical powder can be subdivided into individual doses to provides the exact content of an active pharmaceutical ingredient (API) $[1,2]$ to ensure the quality, safety and therapeutic effect of the drug [3]. As the most critical quality attribute (CQA) of mixed intermediate, blend uniformity (BU) is affected by a number of factors including raw material properties, blending equipment and operations, and environmental conditions [4,5]. In order to effectively monitor the CQA and system dynamic changes of the mixing process, the pharmaceutical industry is encouraged to adopt new process analysis methods under the American Food and Drug Administration (FDA) guidance on process analytical technology (PAT) [6]. Many techniques such as near infrared (NIR) spectroscopy [7-10], Raman spectroscopy (RS) [3,11] and chemical imaging (CI) $[12,13]$ have been reported on determination of BU. Compared with the stratified sampling and offline analysis mode, these online methods enable high frequency sampling, multi-point detection, real time and non-invasive process control, as well as increased production efficiency and reduced operation costs.

The NIR spectroscopy was most widely reported to be used in pharmaceutical mixing unit [14-18]. The NIR data have to be processed by chemometric methods to obtain meaningful results. Available methods can be roughly divided into two types: The qualitative and the quantitative. For both methods, the NIR data carrying the information of the uniformity state or the API concentrations were known beforehand and were used to build the calibration set. Since the physiochemical characteristics of powders such as particle size, shape, surface properties, interparticle forces, density, flowability, and moisture content play a critical role on the blend performance [19-23], a representative sample set covering as much as variability of material properties such as API concentrations, grades, and density was vital to achieve the calibration robustness [24-26]. Nevertheless, the static calibration model, even from a detailed design of an experiment, cannot cover all the varying effects of scale, environment, and powder properties, compromising model reliability [27].

Alternatively, a more flexible way that removes some challenges of both qualitative and quantitative methods has become increasingly attractive $[27,28]$. A typical version of such methods is moving window $\mathrm{F}$ test (MW-F test) derived from the Caterpillar algorithm, the main idea of which is to compare the current variation of the process with its recent variation $[29,30]$. The MW-F test method relates the inhomogeneous risks to the regulatory BU requirement, and the test criteria is set according to the F statistics at given significance level. It is adaptive in nature, offers easier calibrations, and is designed to be suitable for various situations such as scale-up and transfer between different blenders. Currently, the adaptive method was proven to be efficient in both batch and continuous blending processes $[8,17]$. However, the available applications were product specific, and only a limited number of formulation materials including the APIs of anhydrous theophylline and excipients of lactose monohydrate, microcrystalline cellulose (MCC), corn starch and dibasic calcium phosphate were investigated. The impact of material properties on blend metrics is rare and not thoroughly studied.

Many pharmaceutical powders are known to be cohesive and have poor flowability, meaning that they have strong interparticle cohesive forces higher than the particle's own weight. According to Geldart's classification of powders [31], particles with size lower that $30 \mu \mathrm{m}$ are referred to as cohesive powders. Besides, particles with size below $100 \mu \mathrm{m}$ are generally considered to show a degree of cohesiveness [32]. The blending of cohesive powders is more challenging because the interparticle van der Waals force can restrict the de-agglomeration of fine particles [33,34]. Understanding the blending performance of different cohesive materials under online spectroscopic monitoring conditions would be valuable information for the blending process engineering design, development and scale up.

Generally speaking, the MEMS NIR spectrometer, whose polychromatic light is directed onto the MEMS-chip, has a lower resolution and narrower wave number ranges compared to the bench top NIR device [35]. However, the MEMS devices have the advantages of no expensive fiber optic cables, a small size, minimal system maintenance and dust resistance, all of which enable favorable 
performance in challenging good manufacturing practice (GMP) -regulated pharmaceutical process environments [36]. In this paper, an MEMS NIR sensor, which was built specifically for blend analysis and had high spectral resolution $\left(4 \mathrm{~cm}^{-1}\right)$, was incorporated into the online monitoring platform for the blending process of binary mixes consisting of the natural product powders (NPPs) and the excipient. NPPs are multicomponent in nature and were expected to exhibit more physical variation. The blending endpoint was detected by an adaptive modeling algorithm, which was calibration free and was designed to be feasible for different powder systems. Parameters of the adaptive algorithm were optimized through six batches of pilot experiments. Then, the algorithm was used to detect the blending endpoints of 16 kinds of NPPs during their industrial production in $3000 \mathrm{~L}$ bins, which provided higher drop heights for the cohesive powder to develop enough shear rate and facilitate both macro- and micro-mixing [37-39]. The online homogeneity judgement results were validated by off-line sampling and an HPLC analysis of API content. Moreover, the physical properties of NPPs and the excipient were fully characterized. The critical material attributes (CMAs) affecting the blending endpoints for the NPP-excipient binary powder system were identified. Under the framework of quality by design $(\mathrm{QbD})$ and process analytical technology (PAT), the online MEMS-based NIR technique combined with modified adaptive algorithm facilitated a deeper understanding of the mixing process for cohesive powers.

\section{Materials and Methods}

\subsection{Materials}

Twenty-two kinds of natural product powders and dextrin (Batch No. 16010220160102) were provided by Beijing Tcmages Pharmaceutical Co., Ltd. All NPPs were manufactured in a GMP-certified facility by the same preparation processes, such as the pretreatment of herbs, water extraction, concentration and spray drying. However, one major problem of quality control lies in the unstable yield of the extracts, since the quality of raw natural materials could fluctuate from batch to batch [40,41]. Consequently, it was required to add soluble excipients (e.g., dextrin) to the extracts through the mixing process to adjust the weight consistency, which is convenient for clinical application. The weight proportions of added dextrin are given in Table 1, which provides an ideal random design of experiment to study mixing process of binary cohesive powders. The first 6 batches of NPPs (materials No. 1-6) were used in the pilot experiment and the materials No. 7-22 were used in the industrial production. The reference substance of each NPP for HPLC analysis was purchased from the National Institutes for Food and Drug Control. The information of the corresponding reference substances is shown in Table 1.

Table 1. Names and batch numbers of materials used.

\begin{tabular}{cccc}
\hline $\begin{array}{c}\text { Material } \\
\text { No. }\end{array}$ & $\begin{array}{c}\text { NPP Powder } \\
\text { (Lot Number) }\end{array}$ & $\begin{array}{c}\text { Reference Substance for HPLC } \\
\text { (Lot Number) }\end{array}$ & $\begin{array}{c}\text { Proportion of } \\
\text { Dextrin Added } \\
\mathbf{( \% )}\end{array}$ \\
\hline 1 & Paeoniae Radix Alba (J1600160) & Paeoniflorin (110736-201438) & 3.75 \\
\hline 2 & $\begin{array}{c}\text { Processed Fructus xanthii } \\
\text { (J1600481) }\end{array}$ & Chlorogenic acid (110753-201415) & 10.02 \\
\hline 3 & $\begin{array}{c}\text { Processed toasted almond } \\
\text { (J1502067) }\end{array}$ & Amygdalin (J1502067) & 1.60 \\
\hline 4 & Lonicerae Japonicae Flos (J1600420) & Chlorogenic acid (110753-201415) & 2.50 \\
\hline 5 & $\begin{array}{c}\text { Processed semen plataginis } \\
\text { (J1600260) }\end{array}$ & Geniposide (J1600260) & 6.89 \\
\hline 6 & Alismatis Rhizoma (J1502050) & 23-Acetyl-Alismol & 13.78 \\
\hline 7 & Lonicerae Japonicae Flos (J1601959) & Chlorogenic acid (110753-201415) & 5.72 \\
\hline
\end{tabular}


Table 1. Cont.

\begin{tabular}{|c|c|c|c|}
\hline $\begin{array}{l}\text { Material } \\
\text { No. }\end{array}$ & $\begin{array}{l}\text { NPP Powder } \\
\text { (Lot Number) }\end{array}$ & $\begin{array}{l}\text { Reference Substance for HPLC } \\
\text { (Lot Number) }\end{array}$ & $\begin{array}{c}\text { Proportion of } \\
\text { Dextrin Added } \\
(\%)\end{array}$ \\
\hline 8 & Ecliptae Herba (J1601771) & Wedelolactone (110773-201313) & 10.59 \\
\hline 9 & Cibotii Rhizoma (J1601774) & $\begin{array}{l}\text { Protocatechuic Acid } \\
\quad(110809-200604)\end{array}$ & 3.34 \\
\hline 10 & $\begin{array}{l}\text { Glycyrrhizae radix et rhizome } \\
\text { Praeparata cum melle (J1601741) }\end{array}$ & Liquiritin (111610-201106) & 12.14 \\
\hline 11 & Alismatis Rhizoma (J1601527) & $\begin{array}{l}\text { 23-Acetyl-Alismol } \\
(111846-201504)\end{array}$ & 21.96 \\
\hline 12 & Belamcandae Rhizoma (J1601762) & Irigenin (111557-200602) & 5.56 \\
\hline 13 & Radix Paeoniae Rubra (J1601588) & Paeoniflorin (110736-201640) & 4.13 \\
\hline 14 & Scrophulariae Radix (J1601477) & Harpagoside (111730-201307) & 12.40 \\
\hline 15 & Chuanxiong Rhizoma (J1601790) & Ferulic Acid (110773-201313) & 10.21 \\
\hline 16 & Taraxaci Herba (J1601803) & Caffeic Acid (110885-200102) & 10.58 \\
\hline 17 & $\begin{array}{l}\text { Processed Radix Polygalae } \\
\text { (J1601902) }\end{array}$ & 3,6-Disinapoylsucrose (J1601902) & 2.98 \\
\hline 18 & Rhei Radix Et Rhizoma (J1601751) & Aloe-Emodine (110795-201308) & 7.86 \\
\hline 19 & Angelica sinensis (J1601665) & Ferulic Acid (1110773-201313) & 4.80 \\
\hline 20 & Dipsaci Radix (J1601913) & Asperosaponin (111685-201304) & 20.00 \\
\hline 21 & Mume Fructus (J1601679) & Citric Acid (110773-201313) & 4.30 \\
\hline 22 & Cirsii Herba (J1601841) & Linarin (111528-201308) & 2.67 \\
\hline
\end{tabular}

\subsection{Physical Characterization of Powder Materials}

Nineteen physical parameters were used to comprehensively characterize the properties of NPPs and dextrin. Whenever possible, the pharmacopoeia test methods were preferred. Before measurement, all powders were sifted through a 24-mesh size sieve to remove any clumps. Each parameter value was the mean of three replicates.

Bulk density $(D a)$ : The bulk density was measured according to the method described in Section 2.9.34 of European Pharmacopoeia 9.0 (E.P. 9.0). In simple terms, $100 \mathrm{~g}(\mathrm{~m})$ of powder was filled into a $250 \mathrm{ml}$ graduated cylinder with a funnel, and the resulting volume $(\mathrm{Va})$ was recorded. Bulk density was computed using Equation (1):

$$
D a=m / V a
$$

Tapped density $\left(D_{c}\right)$ : The tapped volume $\left(V_{c}\right)$ was obtained after 2500 strokes using a tap density tester (HY-100; Dandong Hengyu Instrument Ltd., Dandong, China). This parameter was computed using Equation (2):

$$
D c=m / V c
$$

Based on the test results of bulk density and tapped density, inter-particle porosity (Ie), Carr index (IC) and Hausner ratio (IH) were calculated using Equations (3)-(5), respectively.

$$
\begin{gathered}
I e=(D c-D a) /(D c \times D a) \\
I c=(D c-D a) / D c \times 100 \\
I H=D c / D a
\end{gathered}
$$


The angle of repose $(\alpha)$ was measured according to the official method illustrated in Section 2.9.36 under E.P. 9.0. The sample was poured through a funnel onto a platform until a stable powder cone was formed. Then the height $(h)$ and the diameter $(r)$ of the powder cone was measured. Finally, the angle of repose was calculated using Equation (6):

$$
\tan (\alpha)=2 h / r
$$

Flow time ( $\left.t^{\prime \prime}\right)$ was measured according to the official method illustrated in Section 2.9.16 under E.P. 9.0. A $100 \mathrm{~g}$ sample was added into a dry funnel whose bottom opening had been blocked. The times needed for the entire sample to flow out of the funnel were recorded after unblock the bottom.

Moisture content $(M C)$ was measured using the Sartorius MA35 instrument (Sartorius AG, Goettingen, Germany). About $2.00 \mathrm{~g}$ of the test powder was tiled on a sample tray and heated at $105^{\circ} \mathrm{C}$. The percentage of moisture content was recorded until a constant weight was obtained.

The percentage of particles measuring $<20 \mu \mathrm{m}(p f)$ was determined using a laser particle size analyzer (BT 2001; Dandong Bettersize Instrument Ltd., Dandong, China) according to the official method in Section 2.9.31 of E.P. 9.0. The particle size distribution of the powder was measured using air as a dispersion medium, and the percentage of the powder with a particle size less than $20 \mu \mathrm{m}$ was calculated.

The homogeneity index $(I \theta)$ test method is the same to the particle size analysis by laser light diffraction. Due to the small particle size of the NPP and dextrin, the four sizes used were $0.150,0.075$, 0.050 , and $0.020 \mathrm{~mm}$, and the percentage of powder in each particle size range was calculated. $I \theta$ was calculated according to the Equation (7):

$$
I \theta=\frac{F_{m}}{100+\left(d_{m}-d_{m-1}\right) F_{m-1}+\left(d_{m+1}-d_{m}\right) F_{m+1}+\left(d_{m}-d_{m-2}\right) F_{m-2} \ldots+\left(d_{m}-d_{m+n}\right) F_{m-n}+\left(d_{m+n}-d_{m}\right) F_{m+n}}
$$

where $F_{\mathrm{m}}$ is the percentage of particles in the majority range, $F_{\mathrm{m}-1}$ is the percentage of particles in the range immediately below the majority range, $F_{\mathrm{m}+1}$ is the percentage of particles in the range immediately above the majority range, $\mathrm{n}$ is the order number of the fraction studied under a series with respect to the majority fraction, $d_{\mathrm{m}}$ is the mean diameter of the particles in the majority fraction, $d_{\mathrm{m}-1}$ is the mean diameter of the particles in the fraction of the range immediately below the majority range, and $d_{\mathrm{m}+1}$ is the mean diameter of the particles in the fraction of the range immediately above the majority range.

Hygroscopicity $(H)$ was determined by pharmacopoeia method descripted in Section 5.11 under E.P. 9.0. Under a constant temperature, the ammonium sulfate saturated solution placed at the bottom of the dryer provided a constant humidity environment. Hygroscopicity could be determined by calculating the percentage of increasing weight of powders in the mentioned dryer after $24 \mathrm{~h}$.

According to the particle size distribution curves tested by the laser diffraction instrument, $D_{10}$, $D_{50}$, and $D_{90}$ were the particle sizes at the 10th, 50th, and 90th percentiles, respectively. The width of powder size distribution (Span) was calculated by Equation (8):

$$
\text { Span }=\frac{D_{90}-D_{10}}{D_{50}}
$$

For the particle shape, the powder was pasted on a metal disc and placed on an ion sputtering apparatus (SC7620, Quorum, East Sussex, UK). Then, the surface morphology of the powder was observed using a scanning electron microscope (Quanta250, FEI, Hillsboro, OR, USA). Photographic images of about 40 particles for each sample were analyzed by Image Pro plus 6.3 software (Media Cybernetics, Rockville, MD, USA) to measure various particle shape descriptors, i.e., aspect ratio, roundness, irregularity, and radius ratio. The aspect ratio means a ratio between major axis and minor axis of ellipse equivalent to a particle; a perfect circle has an aspect ratio of 1 . The radius ratio represents ratio between maximum radius and minimum radius, and the max or min radius is a maximum or minimum distance between each particle's centroid position. The irregularity is a ratio between the perimeter and the Feret diameter (the longest length of a particle); with an ideal ratio of $\pi$ 
meaning a perfect circle. The roundness can be calculated by Equation (9). A circular particle will have a roundness equal to 1 , and the other shape will have a roundness greater than 1 .

$$
\text { Roundness }=\frac{\text { Perimenter }}{4 \times \pi \times \text { Area }}
$$

\subsection{Near Infrared Spectroscopy}

The Antaris Target Online Near Infrared Sensor (Thermo Nicolet, Madison, WI, USA) equipped with a semiconductor tunable light source (covering $5500-7500 \mathrm{~cm}^{-1}$ ) was used in the blending process (see Figure 1). For on-line detection, the sensor was firmly mounted onto a flush top of the blend bin (Wuhan Hengda Chang Machinery Equipment Co., Ltd., Wuhan, China) which was modified with a sapphire window. The rotating speed of bins for both the pilot scale and the commercial scale was set constant at $14 \mathrm{r} / \mathrm{min}$. The position of the bin was continuously monitored. When the NIR sensor was rotated between $170^{\circ}$ and $190^{\circ}$, the NIR sensor was triggered to collect the diffuse reflection spectra through the sapphire window. The sample was scanned 8 times to obtain an average spectrum during each rotation. A wireless access point enables successful communications between the computer and the sensor via the 802.11 wireless Ethernet standard. The RESULT software (Thermo Nicolet, Madison, WI, USA) used workflow controls to receive the spectral data and to synchronize data collection with the bin position. The parameters of the NIR were set as follows: $\log (1 / R)$ was absorbance data format, and the spectral scanning rang was within $7100-5500 \mathrm{~cm}^{-1}$. The pilot experiment with a $75 \mathrm{~L}$ bin was carried out, and the resolution and magnification of NIR were, respectively, set to $8 \mathrm{~cm}^{-1}$ and 125. In the actual production process, a $3000 \mathrm{~L}$ bin was used. The magnification and resolution were, respectively, set to 625 and $4 \mathrm{~cm}^{-1}$. The sequence NIR data files collected from time-based blending experiments was achieved in the specified folder on the hard disk. The real-time monitoring of the blending process as well as the detection of the blending endpoint was achieved by the adaptive modeling algorithm.
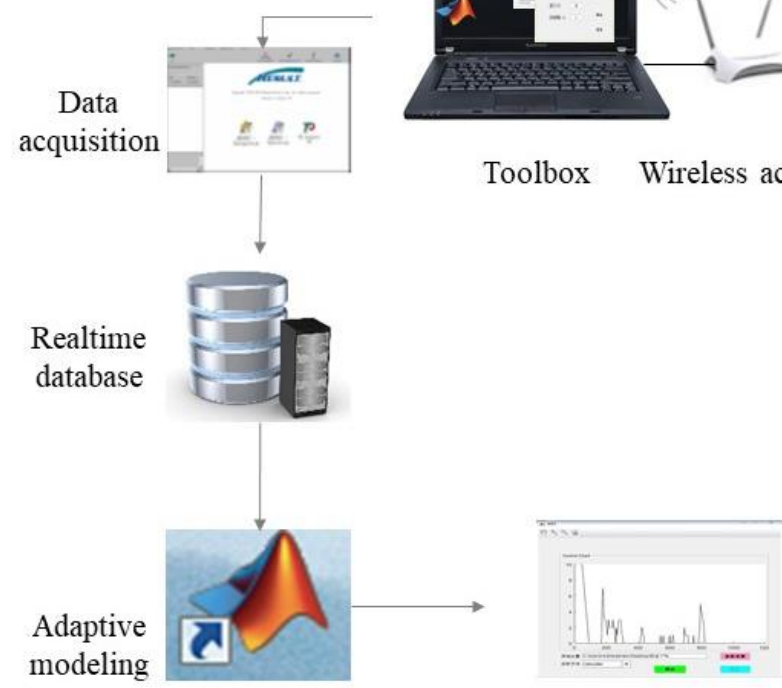

Monitoring window

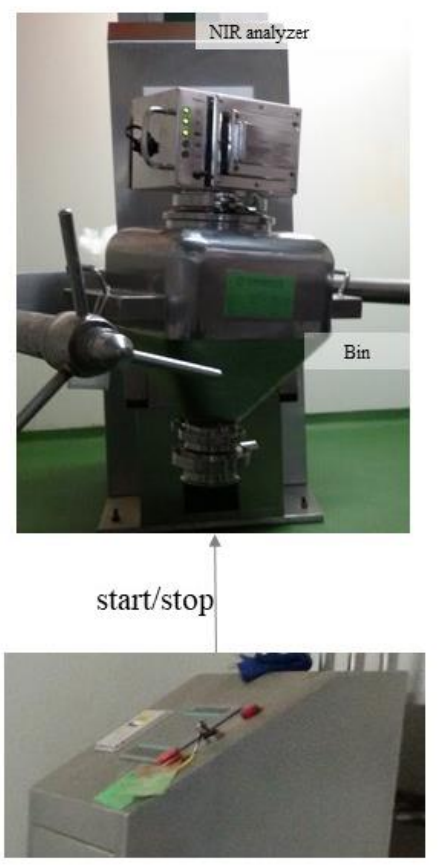

PLC controller

Figure 1. Online near infrared (NIR) control platform for blending endpoint detection. 


\subsection{Principles of the Adaptive Modeling Algorithm}

In this paper, a modified adaptive algorithm including three steps, i.e., dynamic data pretreatment, process variation identification, and reliable homogeneity judgement, was proposed. The detailed procedures of the adaptive algorithm are as follows.

Step 1: The NIR sensor is used to collect the spectral data along with the mixing process and the data are subjected to real-time dynamic pretreatment.

S1-1: At time point $h$, all the raw near infrared data are combined into a matrix $\mathbf{G}$ (size $m \times n$, where $m$ is the number of samples, and $n$ is the number of spectral variables).

S1-2: The chemometric method, e.g., multiplicative scatter correction (MSC) or standard normal variate transformation (SNV), is used to preprocess the spectral matrix $\mathbf{G}$ to obtain the matrix $\mathbf{X}$ (size $m \times n$ ).

S1-3: At the time point $h+1$ (or $h+z$, where $z$ is an integer), the calculation process is repeated from step S1-1.

Step 2: Two windows are established to simultaneously move on the preprocessed NIR data. The data in one window (modeling window) are used to build the principal component analysis (PCA) model and to set the control limit. The data in the other window (prediction window) are monitored and the number of samples larger than critical value is counted.

S2-1: On the matrix $\mathbf{X}$, two parallel sample matrices $\mathbf{A}\left(\right.$ size $\left.w_{1} \times n\right)$ and $\mathbf{B}\left(\right.$ size $\left.w_{2} \times n\right)$ are set, where $w_{1}$ is the number of $\left(m-w_{1}-w_{2}+1\right)$ to $\left(m-w_{2}\right)$ samples in matrix $\mathbf{X}, \mathbf{w}_{2}$ is the number of $\left(m-w_{2}+1\right)$ to $m$ samples in matrix $\mathbf{X}$, and $\mathrm{m} \geq\left(w_{1}+w_{2}\right)$. The $\mathbf{B}$ matrix is used to build the PCA model:

$$
B=T P^{T}+E
$$

In Equation (10), the matrix $\mathbf{T}$ (size $\left.w_{2} \times k\right)$ is the score matrix, the matrix $\mathbf{P}(n \times k)$ is the loading matrix, the matrix $\mathbf{E}\left(w_{2} \times n\right)$ is the residual matrix, and $k$ is number of principal components.

S2-2: Based on the PCA model, the critical value is set according to Equation (11):

$$
D_{\text {crit }}=\frac{k\left(w_{2}^{2}-1\right)}{w_{2}\left(w_{2}-k\right)} F_{\left(k, w_{2}-k, \alpha\right)}
$$

In Equation (11), $F_{\left(k, w_{2}-k, \alpha\right)}$ is the $F$-distribution critical value at degrees of freedom $k$ and $w_{2}-k$, and $\alpha$ is the significance level.

S2-3: The sample data in the matrix $\mathbf{A}$ are projected in the principal component space in the direction of the load $\mathbf{P}$, and the score matrix $\mathbf{T}_{\text {new }}$ (size $w_{1} \times k$ ) of the matrix $\mathbf{A}$ is calculated:

$$
\mathbf{T}_{\text {new }}=\mathbf{A P}
$$

S2-4: The Mahalanobis distance $d_{\mathrm{i}}\left(i=1,2,3, \ldots, w_{1}\right)$ for each sample in matrix $\mathbf{A}$ is calculated using Equation (13):

$$
d_{i}=\left(\mathbf{t}_{i}-\mathbf{m u}\right) \mathbf{S}^{-1}\left(\mathbf{t}_{i}-\mathbf{m u}\right)^{\mathrm{T}}
$$

where the vector $\mathbf{t}_{\mathrm{i}}$ (size $1 \times k$ ) represents the score vector of the sample $i$ in the matrix $\mathbf{T}$, $\mathbf{m u}$ is the mean vector of the matrix $\mathbf{B}$, and $\mathbf{S}$ is the covariance matrix of the matrix $\mathbf{B}$. Comparing the values of di with $D_{\text {crit }}$, the number of atypical samples in matrix $\mathbf{A}$ is counted.

Step 3: Along with the proceeding of the mixing process, the number of atypical samples generated at each time point is recorded and displayed in the graphical user interface (GUI). In order to enhance the reliability of end-point detection, a lag time (LT) could be set. When the number of atypical samples is kept at zero in the LT interval, the materials in the mixer are considered to reach the blend homogeneous state.

Several advantages can be found in this modified adaptive algorithm. First, at the current monitoring window, all previous NIR spectra are preprocessed to reflect the system dynamics in real time. Second, the modelling window is situated behind the prediction window, since the former 
window is considered to contain more variation information than the latter window along with the proceeding of mixing process. Third, the reliability of mixing endpoint detection is improved by setting the LT reasonably.

\subsection{Reference Analysis}

To validate the reliability of the blending homogeneity detected by the online NIR monitoring system, a stratified sampling plan was made. Immediately after the blending endpoint was found, the blender was stopped by the programmable logic controller (PLC). Samples were taken by a thief probe at 11 locations of the industrial bin. As shown in Figure 2, sampling locations 1,2 and 3 stand for the upper powder bed, sampling locations 4,5 and 6 stand for the bin corner, sampling locations 7 , 8 and 9 represent the middle layer of the powder bed, sampling site 10 represents the lower surface of the powder bed and the tank blind angle, and sampling site 11 denotes the sampling site on the axis of the powder bed. Figure 2 shows 11 sampling locations. The contents of APIs were detected by an Agilent 1260 High Performance Liquid Chromatograph (Agilent, Santa Clara, CA, USA,) with a UV detection scheme. The chromatographic conditions referred to used a $250 \mathrm{~mm} \times 4.6 \mathrm{~mm}$ column (Agilent Extend C-18, Agilent, Santa Clara, CA, USA,), and the column temperature was maintained at $25^{\circ} \mathrm{C}$. Other information, such as the mobile phase and the detection wavelength, are listed in Table S1 (Supplementary Materials). All HPLC methods were validated in accordance with the Chinese Pharmacopoeia (ChP 2015).

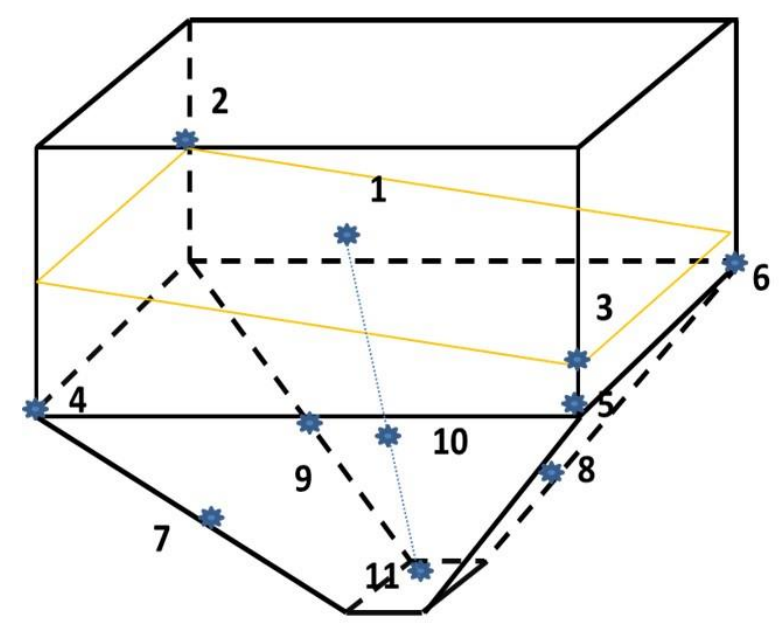

Figure 2. The stratified sampling plan for the industrial production. The yellow frame represents the surface of the powder bed, and the blue stars represents stratified sampling sites.

\subsection{Software}

The homemade KRT software running on the MATLAB 2009a platform (MathWorks, Natick, MA, USA) could realize all steps of adaptive algorithms and can be operated at the manufacturing site. The partial least square (PLS) models were developed by SIMCA 13.0 software (Umetrics, Umea, Sweden). An analysis of variance (ANOVA) was performed on SAS 8.0 software (SAS, Carey, NC, USA).

\section{Results and Discussion}

\subsection{Physical Properties of Powder Materials}

The measured 19 physical quality attributes for 22 NPPs and dextrin (material No. 23) are shown in Table 2. All tested material properties were stored in the iTCM database [42]. The SEM images of all materials are displayed in Figure 3 and Figure S1 (Supplementary Materials). This information reflected different aspects of powder properties, such as particle shape, particle size, density, flowability and stability. 
Table 2. The physical properties measured for 23 materials.

\begin{tabular}{|c|c|c|c|c|c|c|c|c|c|c|c|c|c|c|c|c|c|c|c|}
\hline Number & $D a$ & $H$ & $M C$ & Ic & Ie & $\alpha$ & $I H$ & $p f$ & $I \theta$ & $D c$ & Span & $t$ & $D_{10}$ & $D_{50}$ & $D_{90}$ & $\begin{array}{l}\text { Aspect } \\
\text { Ratio }\end{array}$ & $\begin{array}{l}\text { Radius } \\
\text { Ratio }\end{array}$ & Roundness & Irregularity \\
\hline 1 & 0.47 & 16.23 & 6.70 & 31.60 & 0.67 & 43.83 & 1.46 & 52.04 & 0.002296 & 0.69 & 2.93 & $+\infty$ & 4.746 & 18.950 & 60.30 & 1.21 & 1.44 & 1.04 & 2.89 \\
\hline 2 & 0.44 & 21.42 & 4.71 & 18.69 & 0.42 & 33.05 & 1.23 & 55.13 & 0.001938 & 0.54 & 2.88 & $+\infty$ & 4.425 & 17.243 & 54.00 & 1.25 & 1.66 & 1.19 & 3.10 \\
\hline 3 & 0.13 & 23.22 & 7.04 & 39.47 & 2.92 & 49.95 & 1.65 & 68.86 & 0.000786 & 0.22 & 4.08 & $+\infty$ & 3.564 & 12.663 & 55.69 & 1.26 & 1.74 & 1.09 & 2.89 \\
\hline 4 & 0.39 & 19.90 & 7.36 & 34.50 & 0.89 & 42.66 & 1.53 & 49.35 & 0.002340 & 0.59 & 3.49 & $+\infty$ & 4.945 & 20.337 & 75.88 & 1.34 & 2.79 & 1.29 & 2.93 \\
\hline 5 & 0.37 & 17.79 & 3.41 & 30.16 & 0.81 & 36.31 & 1.43 & 75.41 & 0.000664 & 0.53 & 2.59 & $+\infty$ & 3.670 & 11.647 & 33.88 & 1.33 & 1.95 & 1.16 & 2.91 \\
\hline 6 & 0.51 & 20.62 & 8.39 & 31.16 & 0.61 & 38.29 & 1.45 & 42.78 & 0.003321 & 0.75 & 2.85 & $+\infty$ & 4.787 & 24.477 & 74.48 & 1.48 & 1.98 & 1.22 & 2.81 \\
\hline 7 & 0.44 & 24.54 & 5.36 & 21.86 & 0.50 & 39.31 & 1.28 & 74.73 & 0.000455 & 0.56 & 2.24 & $+\infty$ & 4.746 & 12.037 & 30.68 & 1.30 & 1.67 & 1.08 & 2.88 \\
\hline 8 & 0.43 & 39.07 & 7.52 & 19.82 & 0.47 & 38.60 & 1.25 & 78.60 & 0.000264 & 0.53 & 2.29 & $+\infty$ & 4.425 & 10.987 & 28.70 & 1.22 & 1.55 & 1.07 & 2.95 \\
\hline 9 & 0.35 & 23.66 & 5.64 & 29.44 & 0.84 & 59.08 & 1.42 & 49.41 & 0.002416 & 0.50 & 2.29 & $+\infty$ & 3.564 & 24.167 & 62.29 & 1.36 & 1.85 & 1.20 & 2.98 \\
\hline 10 & 0.44 & 21.07 & 5.77 & 21.09 & 0.48 & 39.62 & 1.27 & 56.19 & 0.002065 & 0.56 & 3.84 & 29.47 & 4.945 & 13.437 & 55.16 & 1.24 & 1.42 & 1.02 & 2.88 \\
\hline 11 & 0.33 & 30.63 & 8.89 & 42.93 & 1.29 & 50.61 & 1.75 & 71.36 & 0.000390 & 0.58 & 2.21 & $+\infty$ & 3.670 & 13.017 & 32.36 & 1.63 & 2.32 & 1.27 & 2.77 \\
\hline 12 & 0.55 & 25.19 & 7.53 & 31.75 & 0.58 & 44.72 & 1.47 & 45.25 & 0.002769 & 0.81 & 2.57 & $+\infty$ & 4.787 & 22.367 & 63.13 & 1.45 & 1.93 & 1.15 & 2.81 \\
\hline 13 & 0.64 & 16.86 & 3.10 & 35.00 & 0.55 & 45.29 & 1.54 & 43.12 & 0.002651 & 0.98 & 3.90 & $+\infty$ & 3.602 & 25.040 & 103.13 & 1.57 & 1.99 & 1.22 & 2.71 \\
\hline 14 & 0.65 & 20.23 & 3.39 & 35.76 & 0.55 & 47.80 & 1.56 & 32.88 & 0.003975 & 1.01 & 2.68 & $+\infty$ & 3.292 & 39.083 & 108.83 & 1.43 & 1.84 & 1.20 & 2.84 \\
\hline 15 & 0.52 & 15.68 & 5.45 & 40.89 & 0.78 & 55.25 & 1.69 & 25.97 & 0.003418 & 0.88 & 2.48 & $+\infty$ & 6.822 & 48.543 & 127.80 & 1.73 & 2.76 & 1.37 & 2.74 \\
\hline 16 & 0.37 & 37.27 & 8.53 & 36.06 & 0.97 & 51.35 & 1.56 & 75.44 & 0.000492 & 0.58 & 2.44 & $+\infty$ & 3.487 & 11.483 & 31.60 & 1.36 & 1.79 & 1.09 & 2.82 \\
\hline 17 & 0.44 & 22.40 & 2.29 & 41.36 & 0.94 & 59.02 & 1.71 & 56.54 & 0.002176 & 0.75 & 3.86 & $+\infty$ & 3.557 & 15.827 & 60.96 & 1.48 & 2.30 & 1.10 & 2.76 \\
\hline 18 & 0.27 & 22.08 & 7.79 & 44.07 & 1.62 & 59.14 & 1.79 & 73.24 & 0.000951 & 0.49 & 3.87 & $+\infty$ & 5.181 & 9.632 & 40.87 & 1.32 & 1.74 & 1.11 & 2.88 \\
\hline 19 & 0.53 & 23.65 & 7.50 & 31.22 & 0.59 & 47.44 & 1.45 & 43.90 & 0.003109 & 0.77 & 2.56 & $+\infty$ & 3.517 & 23.407 & 65.26 & 1.32 & 1.78 & 1.10 & 2.88 \\
\hline 20 & 0.15 & 27.51 & 6.72 & 47.75 & 3.15 & 58.23 & 1.91 & 99.71 & 0.000000 & 0.29 & 1.64 & $+\infty$ & 4.349 & 6.113 & 12.56 & 1.37 & 2.29 & 1.24 & 2.91 \\
\hline 21 & 0.62 & 17.61 & 7.03 & 19.28 & 0.31 & 34.97 & 1.24 & 35.17 & 0.003842 & 0.76 & 2.30 & $+\infty$ & 7.529 & 27.903 & 71.75 & 1.15 & 1.32 & 1.04 & 3.00 \\
\hline 22 & 0.53 & 39.57 & 7.54 & 37.42 & 0.71 & 51.05 & 1.60 & 88.27 & 0.000000 & 0.84 & 2.62 & 6.83 & 3.489 & 7.460 & 21.25 & 1.49 & 2.12 & 1.20 & 2.83 \\
\hline 23 & 0.45 & 6.05 & 7.44 & 38.04 & 0.85 & 54.31 & 1.61 & 98.10 & 0.000000 & 0.72 & 0.88 & $+\infty$ & 6.476 & 11.723 & 16.85 & 1.21 & 1.27 & 1.03 & 2.89 \\
\hline
\end{tabular}



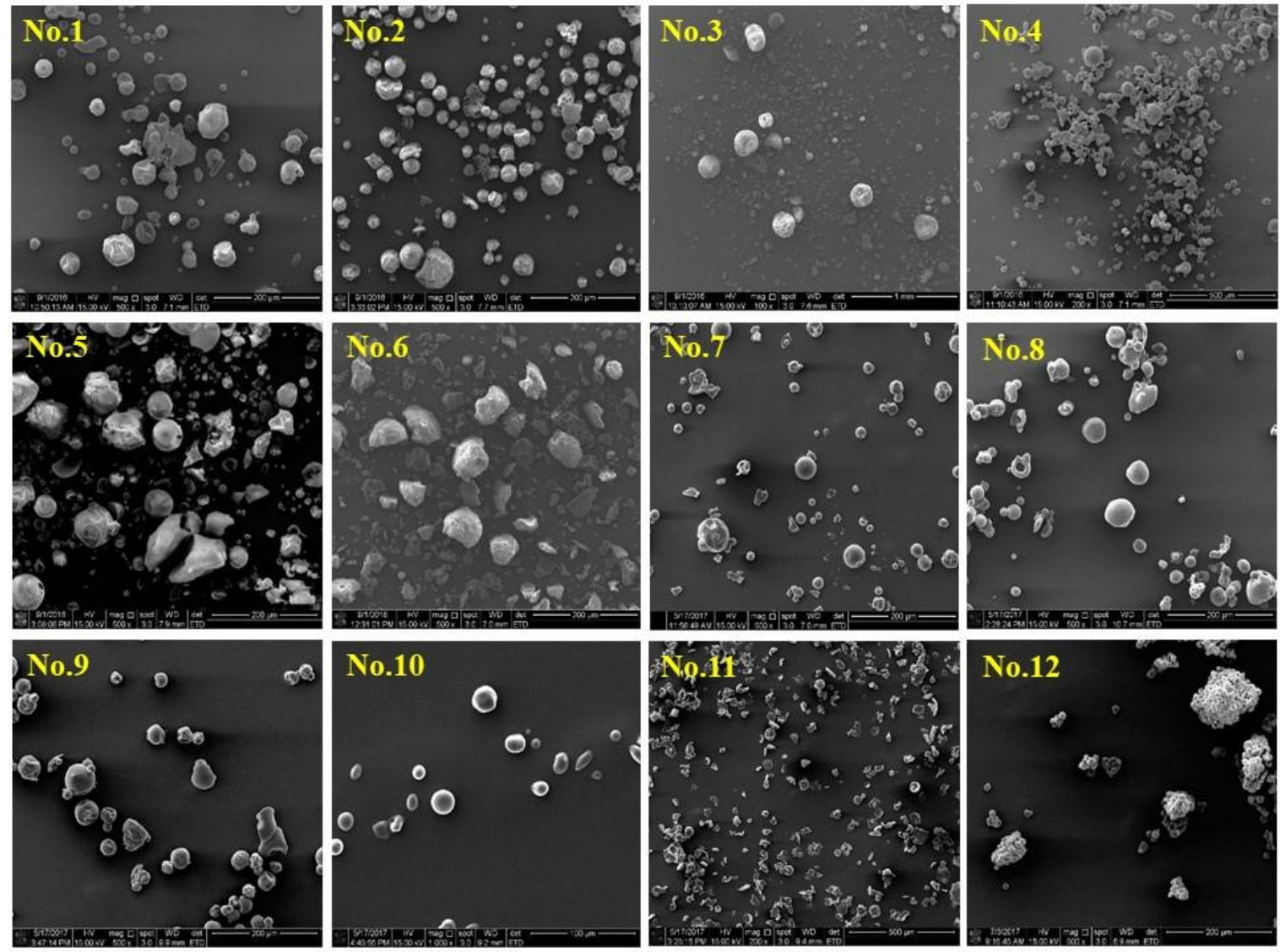

Figure 3. SEM photomicrographs of natural plant powders and dextrin (No. 1-11 are consistent with Table 1, and No. 12 is the dextrin image).

For the particle size, the $D_{10}, D_{50}$ and $D_{90}$ values of NPPs powders were relatively small compared to that of frequently used pharmaceutical excipients in the report [42,43]. Except for dextrin (Span value equal to 0.88 ), the Span values of NPPs were large, indicating that these materials had a wide particle size distribution. The values of $p f$ were large and the values of $I \theta$ were extremely small, indicating that the fine particle content (FPC) in these materials were high. The $D_{50}$ values of these materials were within a range of 6.11-48.54 $\mu \mathrm{m}$. Except for Scrophulariae Radix (No. 14) and Chuanxiong Rhizoma (No. 15), the $D_{50}$ values of all powders were less than $30 \mu \mathrm{m}$. They can be classified into Geldart's group C powders that are cohesive. The range of $D_{90}$ was within $12.56-127.80 \mu \mathrm{m}$, and only three materials' $D_{90}$ values were larger than $100 \mu \mathrm{m}$. This indicates that most powders in the experiment had cohesive properties.

With respect to density properties, the fluctuations of $D a$ and $D c$ values were relatively large. Additionally, there was a strong linear relationship between $D a$ and $D c\left(R^{2}=0.87\right)$. The values of Ie varied greatly from 0.31 to 3.15 , which meant that different voids may be formed during powder accumulation. The values of $I H$ had a relatively wide range (1.23-1.91), and the IC values (18.69-47.75) changed obviously. Both $I H$ and $I C$ are qualitative indicators of the cohesiveness of granular materials. In accordance with Geldart et al. [44], particles with $I H$ values larger than 1.4 were classified into group $C$ powders. From the perspective of $I H$, it was found that 18 batches of powders in the experiment were cohesive powders. According to the E.P. 9.0, when the IH was greater than 1.35 or the IC value was greater than 26 , the flowability of powder was considered poor. Based on the experimental data and pharmacopoeia standards, the flow properties of most materials in the experiment were generally poor. As revealed by Capece et al. [45,46], the inter-particle cohesiveness correlated well to the powder flowability. Poor flowability indicated greater inter-particle cohesiveness. However, the $I H$ values of processed Fructus Xanthii (No. 2) and Mume Fructus (No. 21) were less than 1.25, and the 
corresponding IC values were the smallest and the second smallest, respectively. This shows that the two powders behave more like group A powders, which are mildly cohesive. The same phenomenon was also observed by Berthiaux et al.--some powders like talc, whose cohesion was smaller than expected, cannot be classified easily with the comparison between cohesion and the Carr index [47]. The reason may be that the Geldart's classification was only based on particle size and density, and the powder flowability was influenced by a variety of material properties including particle shape and surface compositions.

The flow descriptors of all materials were directly assessed by the flow time $\left(t^{\prime \prime}\right)$ and the angle of repose $(\alpha)$. Angle of repose values ranged between $33.05^{\circ}$ and $59.14^{\circ}$. Except for Glycyrrhizae Radix et Rhizome Praeparata cum Melle (material No. 10) and Cirsii Herba (material No. 22), flow time ( $\left.t^{\prime \prime}\right)$, the values of all powders tended to infinity because they could not freely flow out from the funnel. According to the E.P. 9.0, if the angle of repose is more than $46^{\circ}$, the flow performance is poor. However, for Paeoniae Radix Alba (material No. 1), Lonicerae Japonicae Flos (material No. 4), processed Semen Plataginis (material No. 5), Alismatis Rhizoma (material No. 6), Belamcandae rhizome (material No. 12) and Radix Paeoniae Rubra (material No. 13), the IC and IH values were, respectively, more than 26 and 1.35 , and their $\alpha$ values were lower than $46^{\circ}$, indicating that the same powder may show different flowability with different evaluation methods. This result demonstrate that no single parameter can completely understand flow behavior [48].

With respect to the particle shape factors, it can be seen form Table 2 that the roundness values were in a range of 1.02-1.37. The roundness values of most powders were close to 1 , indicating that the particles approached a circle, while the rest of the powders were not round. The values of the aspect ratio were within the range of 1.15-1.73, and radius ratios fluctuated from 1.27 to 2.79, indicating that some particles were close to circular and some had certain elongation. The descriptors of irregularity are ranged from 2.71 to 3.10 , showing that the particles' morphology was different to a certain extent. It is especially noteworthy that the irregularity of processed Fructus Xanthii (3.10) and Mume Fructus (3.00) were closest to $\pi$, indicating that they were closer to the circle. This may be a reason for their good flowability. Additionally, it was clear from the SEM image (Figure 3 and Figure S1 in Supplementary Materials) that the particles were of different sizes, and this could be confirmed by particle size distribution of these powders. Though these particles still exhibited inhomogeneous shapes, there were almost no acicular or sharp-edged structures. In particular, primary particles of dextrin (No. 12 in Figure 3) could be agglomerated to larger unit, which may have altered their size and shape.

For the stability factor, the $M C$ values were in a range from 2.29 to 8.89 . By contrast, the range of hygroscopicity $(H)$ was extremely large from 6.05 to 39.57 . The $H$ values of all NPP materials were greater than $15 \%$, indicating they were very hygroscopic according to the E.P. 9.0 standards in Section 5.11. The reason for the high hygroscopicity of the NPPs may be that they contain a lot of hydrophilic compounds, such as glycosides, organic acids, carbohydrates, and amino acids [49].

\subsection{Principle Component Analysis of Physical Properties}

In order to discuss the relationship among physical properties of various materials, a PCA model was established, and a detailed explanation can be seen below.

First principal component (PC1): Descriptors of the particles size and density. The first PC explained $35.0 \%$ and predicted $7.82 \%$ of the variability in the properties of the raw materials and excipient. Figure 4 shows that particle size related parameters such as $D_{10}, D_{50}, D_{90}$ and $I \theta$ are located on the right side of the loading scatter plot. The $p f$ is in the opposite direction. A powder with a high FPC will cause $D_{10}, D_{50}, D_{90}$ and $I \theta$ to decrease. The density related descriptors such as $D a$ and $D c$ had positive loading values to the first PC, revealing that powder with high density may have reduced the FPC. Figure 4 illustrates that most powder parameters not only changed with the PC1 but also with the second principal component (PC2). Nevertheless, the $I \theta, p f, H$ and $M C$ are rather unique parameters that combined a strong loading for PC1 with a neutral loading for PC2. 


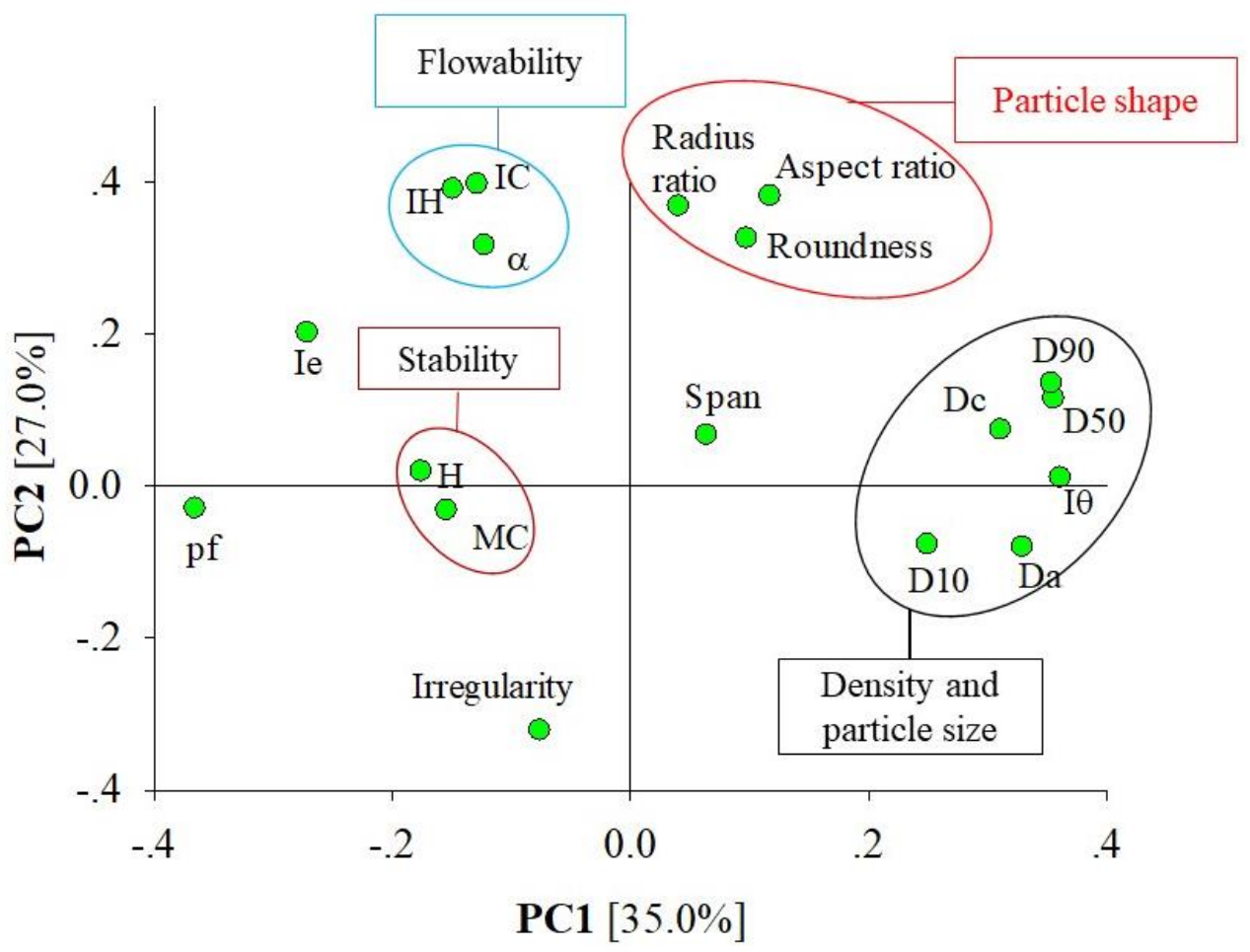

Figure 4. The loading plot of PC1 and PC2.

PC2: Descriptors of the particles shape and flow. The second PC explained $27.0 \%$ and predicted $28.3 \%$ of the variability in the properties of the raw materials and excipient. The shape-related descriptors are displayed on the top right side in Figure 4, indicating that the radius ratio, the aspect ratio and the roundness exhibited moderately positive PC1 loadings and high positive PC2 loadings. As expected, the irregularity descriptor was located at the opposite direction of the loading scatter plot, i.e., the bottom left corner. Overall, the location of irregularity, other shape and flow-related parameters on the loading scatter plot demonstrated common pharmaceutical knowledge: Low irregularity meant that the particles were approximately spherical, and more spherical particles always flowed better.

The raw materials can be clustered in the score scatter plot if they possess similar properties. For example, Angelica sinensis (No. 20) and Dipsaci Radix (No. 21) in Figure 5 are located in the completely opposite direction, because the Ie values of the two powders are the maximum and the minimum, respectively. It can be seen from Figure 5 that the six batches of powders (No. 1-6) used in the pilot experiment are evenly distributed among materials used in the industrial experiment, indicating that the adaptive algorithm optimized by these six batches of powders has the potential of being transferrable to other NPP-dextrin binary systems. 


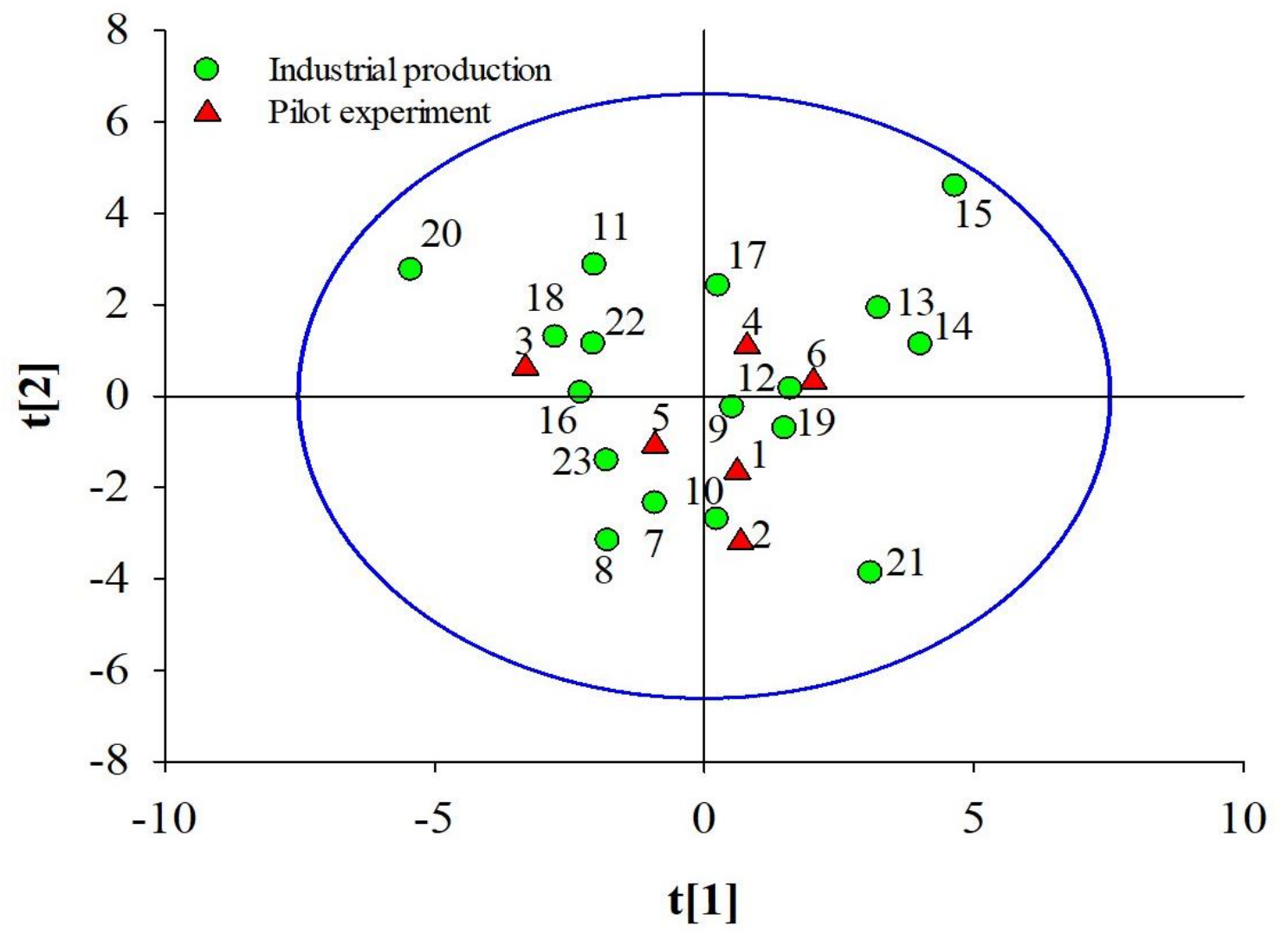

Figure 5. The score plot of PC1 and PC2 (blue ellipse: Hotelling's T ${ }^{2}$ (99\%). No. 1-22 are consistent with Table 1. No. 23 is dextrin. The red triangles represent the materials used in the pilot experiment, and green dots represent the materials used in the industrial production).

\subsection{Pretreatment of NIR Spectra}

Figure 6a shows the original NIR spectra for the dextrin and six kinds of NPPs used in the pilot experiment. It can be seen that the near infrared absorption spectra of the natural plant powders were different from the dextrin, indicating that the NIR sensor has the potential ability to distinguish the NPP and the excipient. In the pilot experiment, 840 NIR spectra for each sample blend were obtained during the mixing process, which lasted for one hour. Figure $6 \mathrm{~b}$ shows changes of NIR spectra in mixing process of Lonicerae Japonicae Flos extract powder-dextrin. The zoom of a specific spectral region (7500 7100 $\mathrm{cm}^{-1}$ ) revealed that the NIR absorption spectrum was not smooth and appeared to fluctuate because of the large noise. Consequently, this regional band was cutoff in the following analysis. Then, the NIR spectra were preprocessed by the SNV method to eliminate the influence of the particle scattering and optical path difference, which was conductive to the optimization of the parameters of the adaptive algorithm. 


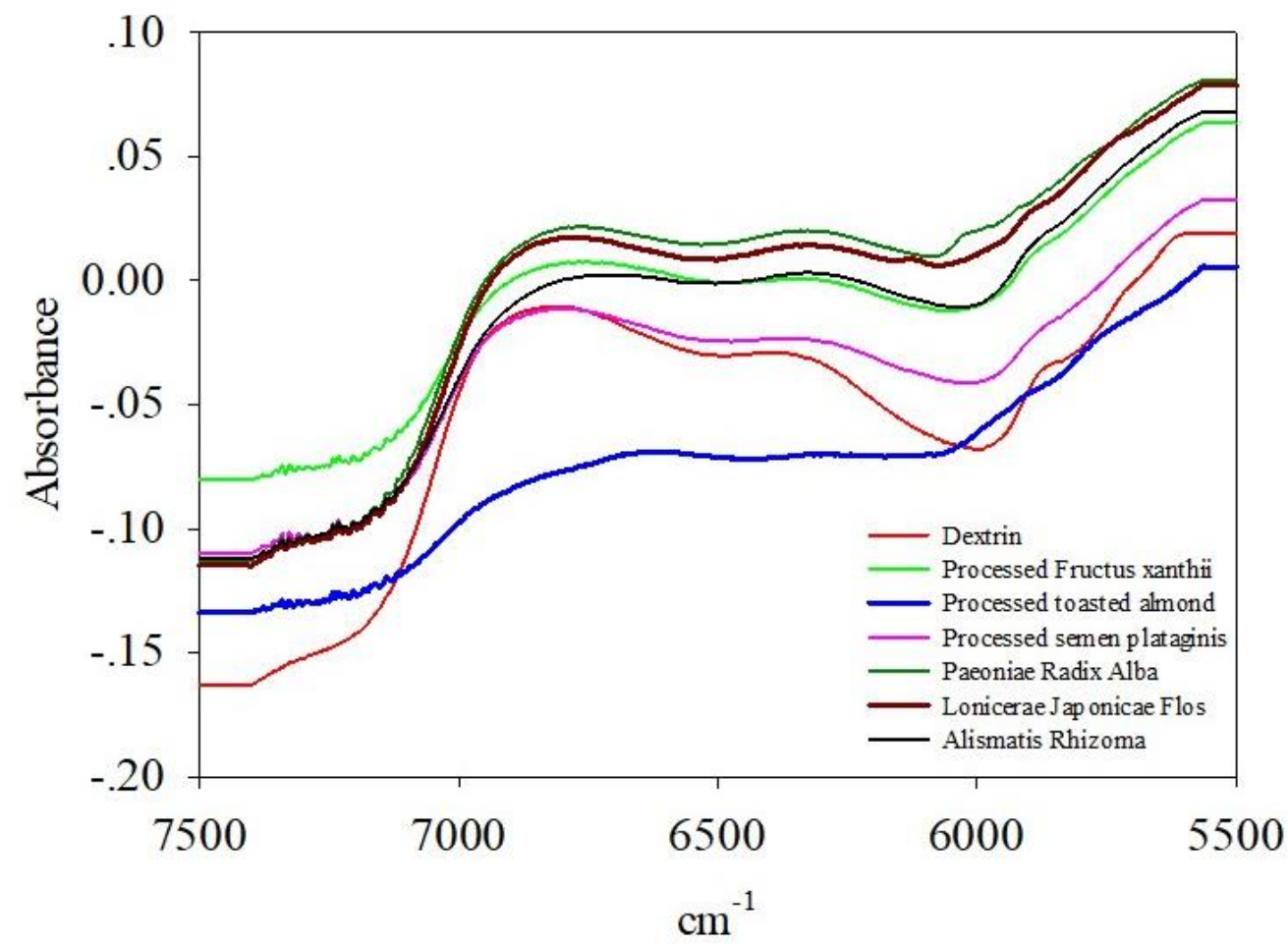

(a)

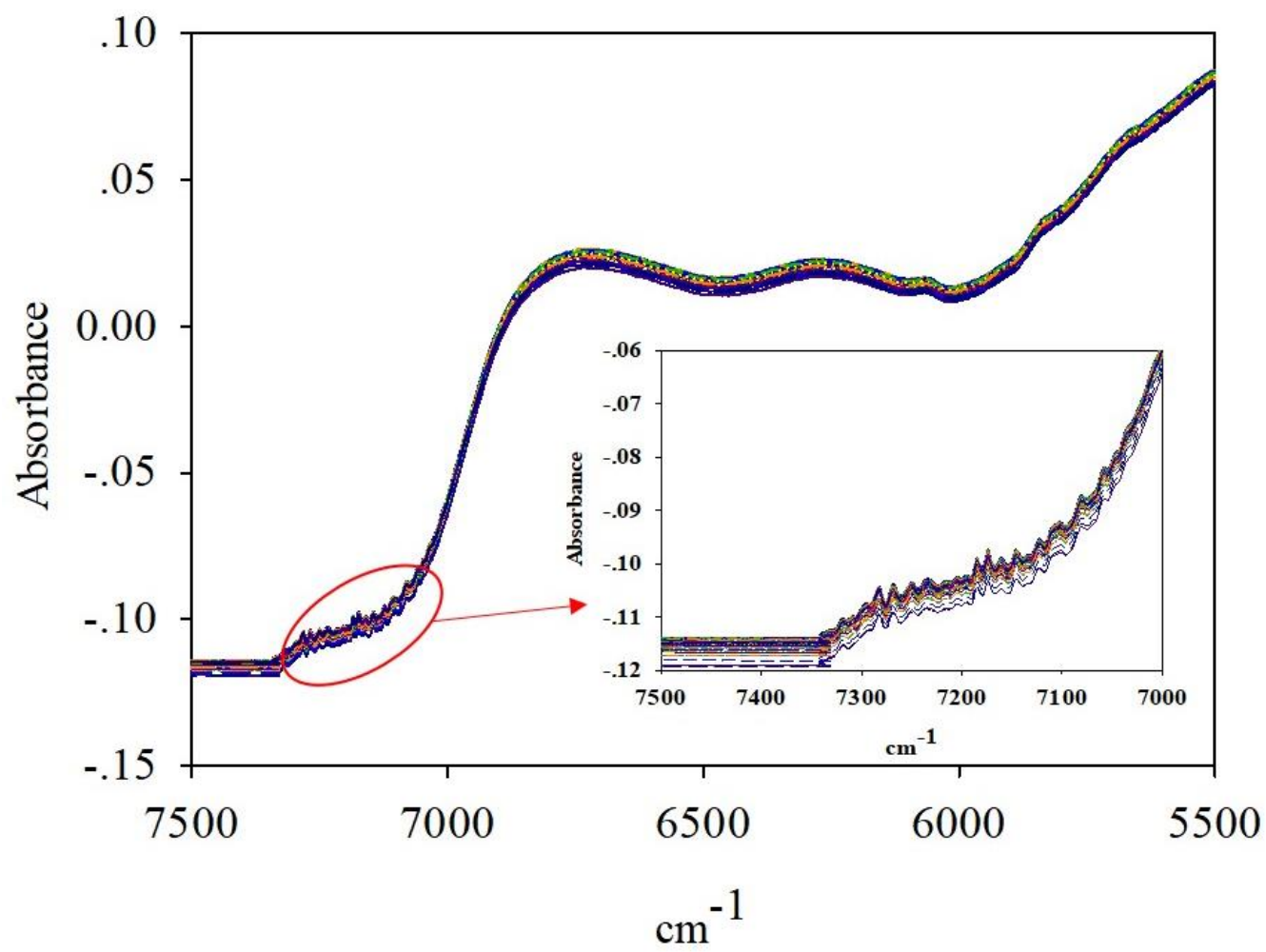

(b)

Figure 6. (a) NIR spectra of the dextrin and natural plant powders used in the pilot experiment. (b) The NIR data from the mixing process of Lonicerae Japonicae Flos extract powder and dextrin. 


\subsection{Parameters Optimization of the Adaptive Algorithm}

Before industrial applications of the NIR spectroscopy, the parameters involved in the adaptive algorithm were optimized in order to make the algorithm sensitive toward process normal variations and robust enough toward signal disturbances. The significance level $\alpha$, which is the $F$ test level in the $D_{\text {crit }}$ control limit calculation formula, was set to 0.05 according to prevailing statistical considerations. Next, the number of principal components $k$ and the window size $w$ were fine-tuned. Six pilot blending experiments using, respectively, NPP materials No. 1-6 in Table 1 were carried out to investigate impacts of the window size and the principal component number on the performance of the adaptive algorithm. Each experiment was run for one hour, and a total of 840 NIR spectra were obtained. At given values of $w$ and $k$, the total number of atypical samples during the blending process were recorded. By changing the values of $w$ and $k$, a response surface for the total number of atypical samples can be plotted, as shown in Figure 7. All the six binary powder systems exerted a similar trend, in that the total number of atypical samples grew rapidly with a reduction of the number of principal components and an increase of the window sizes.

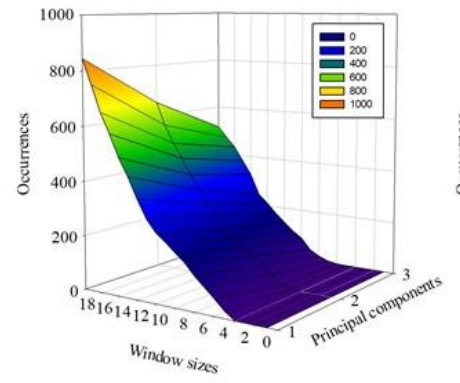

(a) Lonicerae Japonicae Flos

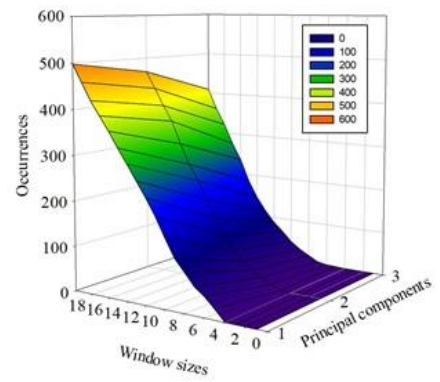

(d)Processed Fructus xanthii

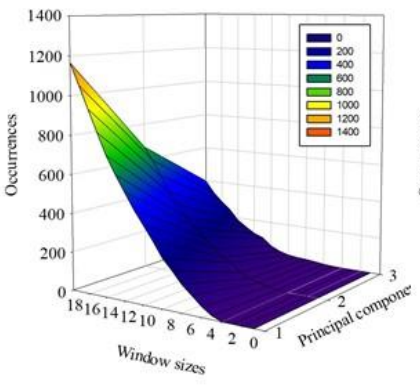

(b) Processed semen plataginis

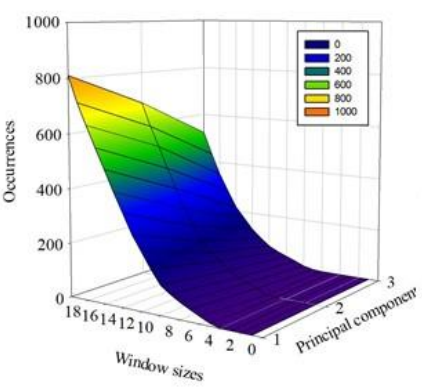

(e) Processed toasted almond

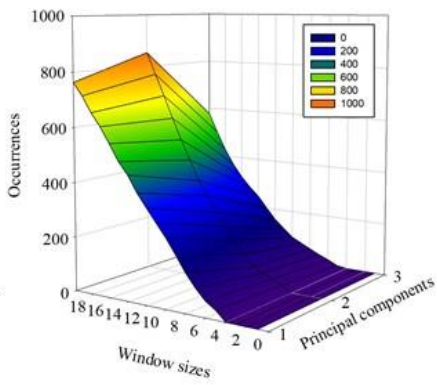

(c) Paeoniae Radix Alba

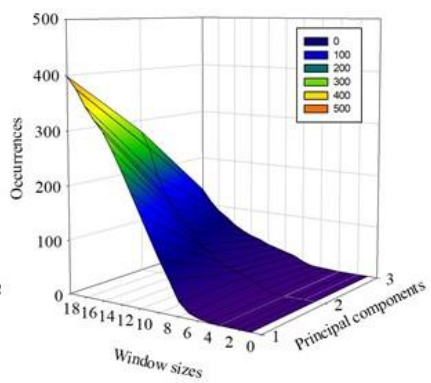

(f) Alismatis Rhizoma

Figure 7. The occurrences response surface of plot of (a) Lonicerae Japonicae Flos; (b) processed semen plataginis; (c) Paeoniae Radix Alba; (d) processed Fructus xanthii; (e) processed toasted almond; (f) Alismatis Rhizoma.

Generally speaking, the modeling window should be wide enough to provide the best possible representation of the changes in all stages of the mixing process [50]. The NIR datasets in the modeling window were then concentrated by the principal component analysis into the first few principal components, which could achieve a high signal to noise ratio. Besides, the combination of $w$ and $k$ with few atypical samples was favored. For the six experiments, the cumulative contribution rate of the two first principal components was more than $99.9 \%$, which means that two first principal components could explain most of variations of the data. Consequently, the optimal number of principal component $k$ of the adaptive algorithm was set to 2 . As for the window size (w), it could be found that when the window size was $1-5$, as the numbers of atypical samples were too small to reflect the mixing dynamics. When the window sizes exceed 15 , the total number of occurrence samples dramatically 
increases. Considering the above criteria for parameters optimization, the window size $(w)$ was set to 10. The optimal settings were combinations with few total atypical samples and a wider windows size.

\subsection{Real Time Detection of the Blending Homogeneity during Industrial Production}

With the optimized parameters $w$ being set to 10 and $k$ being set to 2 , the adaptive algorithm was utilized to monitor the industrial blending process of natural plant granules in real time. Since the mixing bin was $3000 \mathrm{~L}$, the lag time was set to $300 \mathrm{~s}$. If the number of atypical samples continued to be 0 during this lag time, a high assurance for accurate detection of the homogeneity would be provided.

Sixteen kinds of NPPs, i.e., No. 7 to the No. 22 in Table 1, were blended with dextrin in the GMP-certified room. Figure 8 shows an example of the monitoring results from the mixing process of Mume Fructus extract and dextrin. At the beginning of the mixing stage, the atypical samples were rapidly raised then promptly reduced to 0 , indicating that the NPP and dextrin were mixed briskly and reached the homogeneous state. At this stage, the powder may have been in the action of strong convection and may have overcome the hierarchical trend caused by material property differences. With the mixing process progressing, the number of occurrences started to fluctuate within a small range, and the mixed powder at this stage may be in a state of mixing and segregation due to the random diffusion of the powder particles. Finally, in the late stage of the mixing process, the number of overrun samples continued to be 0 within the lag time, indicating that the NPP and dextrin reached the homogeneous state. The stop time for the blender was $33.47 \mathrm{~min}$, and the corresponding endpoint time was $28.47 \mathrm{~min}$. The on-line monitoring results of the other fifteen materials can be seen from Figure S2 in Supplementary Materials. The corresponding endpoint times are listed in Table 3. It can be seen that the mixing time of the Ecliptae herba extract powder and dextrin was the longest ( $36.07 \mathrm{~min}$ ), while that of Cibotii Rhizoma extract powder was the least (2.60 min).

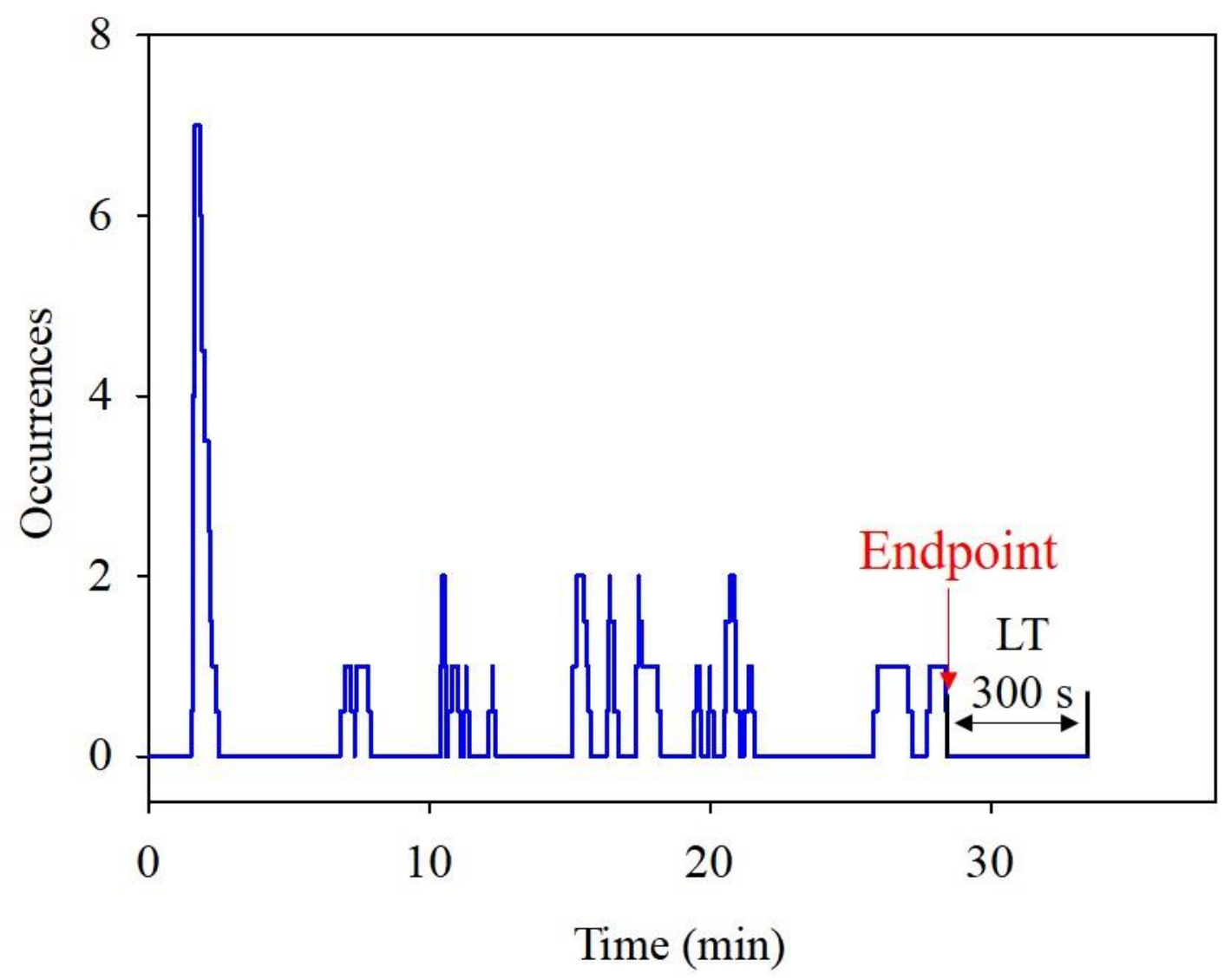

Figure 8. The on-line NIR monitoring results of the mixing process for Mume Fructus extract powder and dextrin. 
Table 3. Results of online endpoint detection and offline ANOVA analysis for 16 batches of industrial production.

\begin{tabular}{cccccc}
\hline $\begin{array}{c}\text { Material } \\
\text { No. }\end{array}$ & Formula Granule & $\begin{array}{c}\text { Time of } \\
\text { Endpoint } \\
\text { (min) }\end{array}$ & $\begin{array}{c}\text { Mean Square } \\
\text { (Between } \\
\text { Group) }\end{array}$ & $\begin{array}{c}\text { Mean Square } \\
\text { (Within } \\
\text { Group) }\end{array}$ & $p$ Value \\
\hline 7 & Lonicerae Japonicae Flos & 2.77 & 0.51 & 0.55 & 0.53 \\
8 & Ecliptae Herba & 36.07 & $4.2 \times 10^{-4}$ & $7.0 \times 10^{-5}$ & $2.0 \times 10^{-4}$ \\
9 & Cibotii Rhizoma & 2.60 & $1.4 \times 10^{-4}$ & $2.7 \times 10^{-4}$ & 0.86 \\
10 & Glycyrrhizae radix et rhizome & 4.33 & 2.9 & 2.0 & 0.23 \\
11 & Praeparata cum melle & & & & 0.11 \\
12 & Alismatis Rhizoma & 9.77 & $1.8 \times 10^{-4}$ & $9.7 \times 10^{-5}$ & 0.081 \\
13 & Belamcandae Rhizoma & 8.83 & $2.0 \times 10^{-4}$ & $1.0 \times 10^{-4}$ & 0.56 \\
14 & Radix Paeoniae Rubra & 17.87 & 1.3 & 1.5 & 0.22 \\
15 & Scrophulariae Radix & 4.57 & $7.6 \times 10^{-5}$ & $5.2 \times 10^{-5}$ & 0.18 \\
16 & Chuanxiong Rhizoma & 3.20 & $3.3 \times 10^{-5}$ & $2.1 \times 10^{-5}$ & $2.0 \times 10^{-4}$ \\
17 & Taraxaci Herba & 13.30 & $2.0 \times 10^{-4}$ & $3.3 \times 10^{-5}$ & 0.34 \\
18 & Processed Radix Polygalae & 9.03 & 0.028 & 0.023 & 0.24 \\
19 & Rhei Radix Et Rhizoma & 4.77 & 0.011 & 0.0077 & 0.62 \\
20 & Angelica sinensis & 6.33 & 0.019 & 0.023 & 0.12 \\
21 & Dipsaci Radix & 10.53 & 4.9 & 2.7 & 0.99 \\
22 & Mume Fructus & 28.47 & 4.2 & 47 & 0.89 \\
\hline
\end{tabular}

In order to verify the accuracy of the detected homogeneity, samples were taken at 11 locations inside the mixing bin by thief sampling immediately after the blender was stopped, according to the predefined sampling protocol. Each location was sampled three times, and the API content of 33 samples were determined by HPLC. An analysis of variance (ANOVA) was used to determine whether the mean contents of 11 sampling sites were different. The mean square between group $\left(\mathrm{MS}_{b}\right)$ and the mean square within group $\left(\mathrm{MS}_{w}\right)$ were calculated to represent the variation between sample means and variation within the samples, respectively. For the one-way ANOVA, the ratio of the between-group variability to the within-group variability followed a probability distribution known as an F-distribution. If the probability $(p)$ was low enough, the null hypothesis that all the group means are equal was rejected using the common significance level of 0.05 . The ANOVA results are provided in Table 3. Except for material No. 8 and material No. 16, the $p$ values were all larger than 0.05 , revealing that there was no difference among the mean content and that the binary powder system reached a homogeneous state. As for material No. 8 and material No. 16, it could be seen that the $\mathrm{MS}_{w}$ values were close to zero and were therefore sensitive to small changes in the $\mathrm{MS}_{b}$ values. The relative standard deviation (RSD) values of the mean content of 11 sampling sites were $1.7 \%$ and $0.67 \%$ for material No. 8 and material No. 16, respectively, indicating that the between-group variability was small $(<3.0 \%)$ and the uniformity was acceptable.

\subsection{Effect of Powder Properties on Mixing Process}

The endpoint time is a measure of the difficulty degree to which the powder system reached a homogeneous state. The longer the mixing time is, the more difficult it is mixed. Through correlation analysis, it could be seen that the relationship between mixing time and proportion of added dextrin was extremely poor $\left(R^{2}<0.01\right)$. Therefore, the factors affecting the mixing time were further explored from the perspective of the physical properties of powdered materials. Because cohesive powders can hardly flow freely, the flow time ( $\left.t^{\prime \prime}\right)$ was not used as an independent variable to develop a model. The independent variables matrix was composed of 16 samples and numeric difference of 18 physical parameters $(D a, H, M C, I C, I e, \alpha, I H, I \theta, p f, D c$, aspect ratio, radius ratio, roundness, irregularity, Span, $D_{10}, D_{50}$, and $D_{90}$ ) between the natural plant powder and the dextrin. Taking Lonicerae Japonicae Flos extract powder as an example, the numeric difference of bulk density $(D a)$ could be obtained by calculating the difference of $D a$ between NPP $(D a=0.446)$ and dextrin $(D a=0.439)$, and then by 
computing the absolute value (0.007). For ease of understanding, the independent variables matrix of physical properties difference is shown in Table S2 (Supplementary Materials). The dependent variables matrix was constructed from the endpoint time of 16 blends detected by NIR with the adaptive algorithm. Subsequently, a PLS model was established to correlate the independent variables and the response variable. From Table 4, it can be seen that the first three latent factors can explain $83.9 \%$ of the Y-variation $(30.4 \%, 43.4 \% \mathrm{~m}$ and $10.1 \%)$. Each PLS factor can explain $33.4 \%, 10.6 \%$ and $20.1 \%$ of the $\mathrm{X}$-variation.

Table 4. The result of the PLS regression model.

\begin{tabular}{cccc}
\hline Components & $\mathbf{R}^{\mathbf{2}}$ xcum $\mathbf{( \% )}$ & $\mathbf{R}^{\mathbf{2}}$ Ycum $\mathbf{( \% )}$ & $\mathbf{Q}^{\mathbf{2}}$ Ycum $\mathbf{( \% )}$ \\
\hline 1 & 33.4 & 30.4 & $-4.49 \times 10^{-2}$ \\
2 & 44 & 73.8 & 10.6 \\
3 & 64.1 & 83.9 & 30.3 \\
\hline
\end{tabular}

A PLS biplot (Figure 9) was drawn to jointly visualize all samples and all variables. A significant correlation of variables can be suggested when variables are projected between the outer circle $(r=1)$ and the middle circle $(\mathrm{r}=0.75)$. There was a strong relationship among flowability variables $\alpha, I H$ and $I C$, among the aspect ratio, the radius ratio and roundness and among variables $D_{50}, D_{90}, p f$ and $I \theta$. Moreover, it can be seen from Figure 9 that $\alpha, I H$, and IC are located near the mixing time, indicating that the differences of flowability properties were positively correlated with the mixing time. The greater the differences of these properties were, the longer the mixing time was needed. The critical raw material attributes (CMAs) influencing the mixing time were investigated by the variable importance in the projection (VIP) index. As shown in Figure 10, irregularity, $\alpha, H$, and IC have VIP values larger than 1 . The error bar of the hygroscopicity passed through zero, reflecting that the influence of $H$ on the mixing process was uncertain. Therefore, irregularity, $\alpha$ and IC were identified as CMAs.

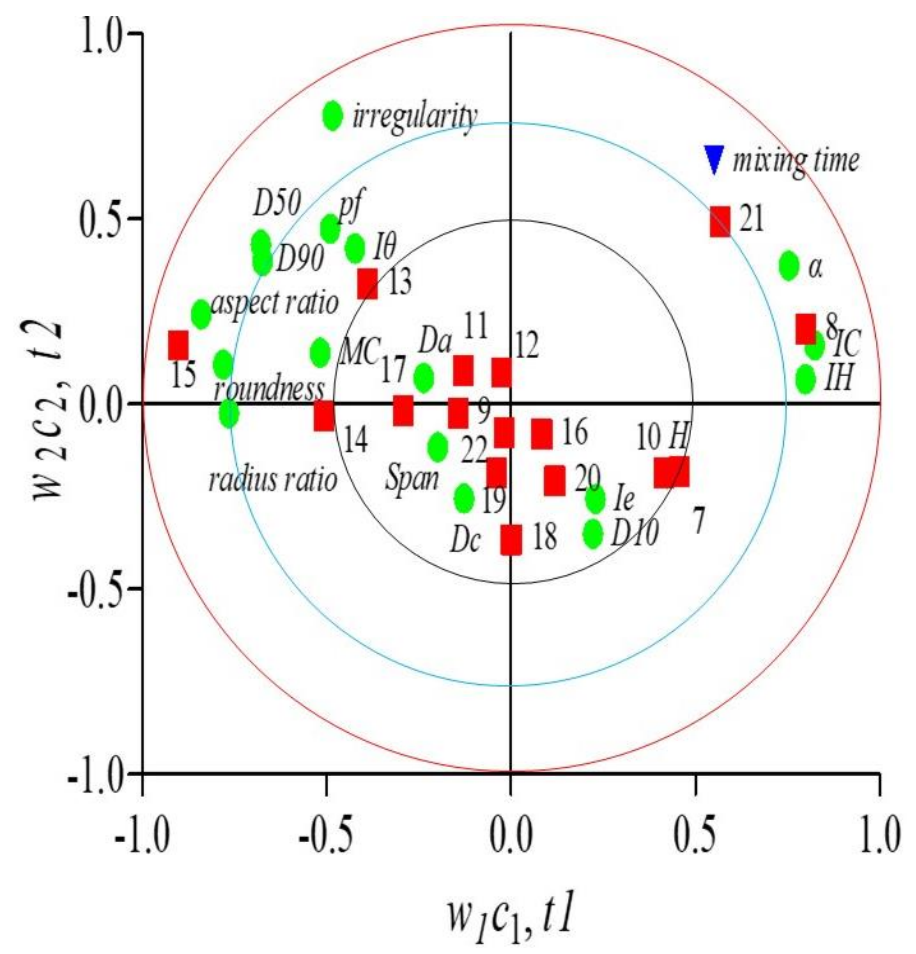

Figure 9. The partial least square (PLS) biplot. The red squares represent binary mixtures, the green dots represent the 18 critical material attributes, the blue triangle denotes mixing time, and the black, blue and red circles represent the inner circle $(r=0.5)$, middle the circle $(r=0.75)$ and the outer circle $(\mathrm{r}=1)$, respectively. 


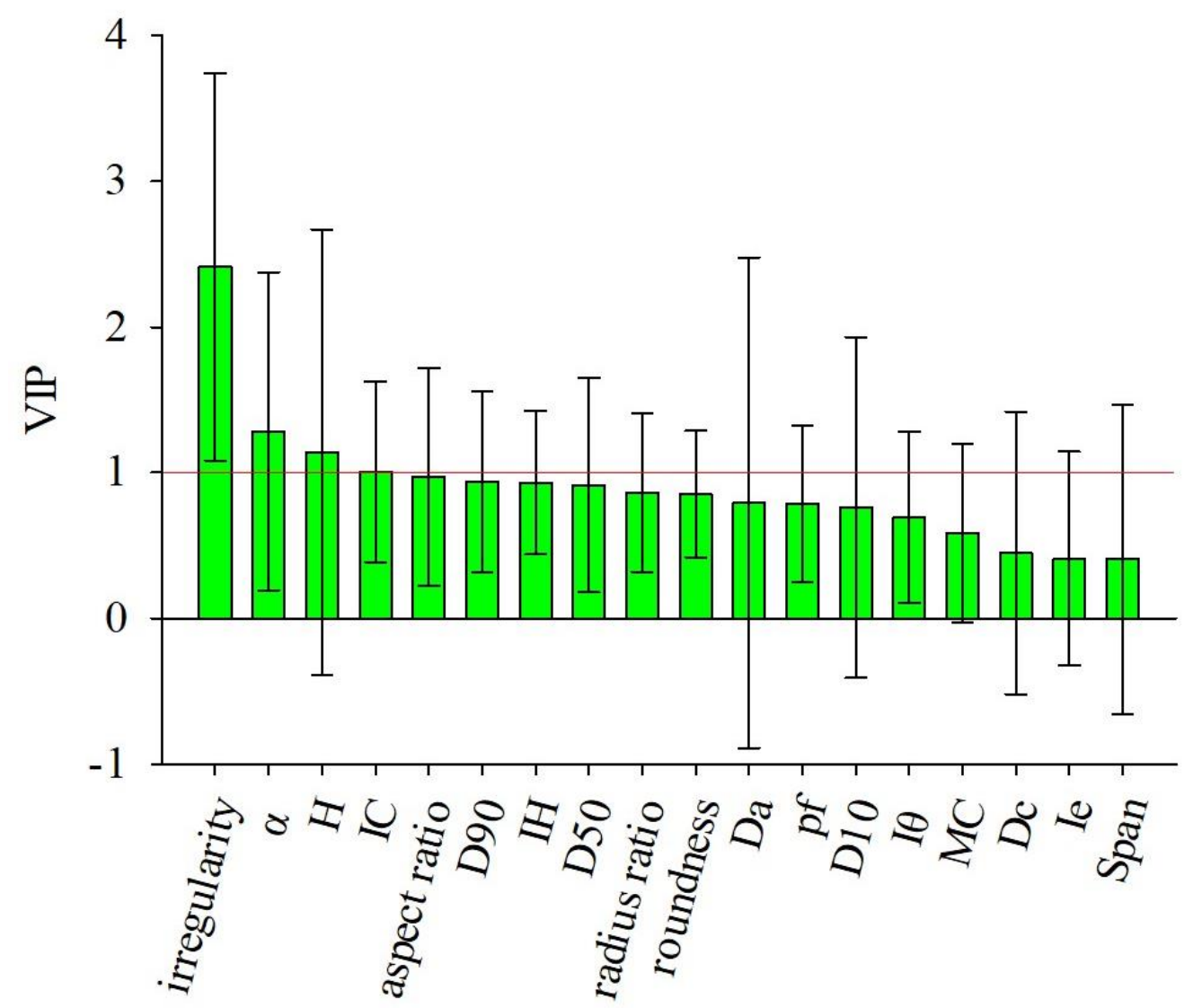

Figure 10. The variable importance in the projection (VIP) indexes for the PLS model (the red line indicates that the VIP equals 1).

Both $\alpha$ and IC were related to the flowability of powders; the quite different flow performance of dextrin and NPP means that the mixing process involved in the movement of high and low cohesive particles. In the blending process, high cohesive particles have more contact with other particles than those of low cohesion [51], causing a low particle velocity. This can seriously affect the movement between powders, leading to low particle diffusion and resulting in a longer mixing time. Among 16 binary powders, natural plant granules of Ecliptae Herba (No. 8) and Mume Fructus (No. 21) have the longest mixing times. It could be seen from Table 2 that the flowability indexes of the two materials were better than that of dextrin. This meant that the cohesion of dextrin may be stronger than that of two materials, and dextrin was hard to be de-agglomerated, making it difficult for dextrin to evenly distribute in binary powders. As for Radix Paeoniae Rubra (No. 13), Scrophulariae Radix (No. 14) and Chuanxiong Rhizoma (No. 15), the differences in the flowability indexes were small-hence, the mixing times were smaller than that of the samples No. 8 and 21. However, due to the biggest difference in the irregularity for the sample No. 13, the mixing time was consequently longer than that of the samples No. 14 and 15.

In the two batches binary mixtures for Alismatis Rhizoma (No. 11) and Rhei Radix Et Rhizoma (No. 18), there was no significant difference in flowability performance. However, the irregularity difference of the two systems was quite different in the Table S2 (Supplementary Materials), which resulted in the mixing time of sample No. 11 (9.77 $\mathrm{min})$ being longer than that of Sample No. 18 (4.77 $\mathrm{min})$. This may be due to fact that the shape of the particles is related to the flowability [52,53]. An irregular shape leads to particle mutual occlusion, hindering particle movement. This is not conductive to the rearrangement and the diffusion of particles. 
Additionally, it can be seen from Table S2 in Supplementary Materials that the No. 20 sample had the largest $D a$ difference. This indicates that higher bulk density ratios may lead to segregation [23], which will affect the mixing process, resulting in prolonged mixing time.

As for Taraxaci Herba (No. 16) and Cirsii Herba (No. 22), the contribution plots for two binary mixtures are shown in Figure 11. In Figure 11a,b, the dominating bars exhibit the $H$ parameter deviates most from the model average, which indicates that the hygroscopicity of the powder can affect mixing time. Hygroscopic powders can increase cohesion and reduce flowability by adsorbing moisture in the air [54], leading to longer mixing time. These results reflected that the mixing process of cohesive powder systems was complex, and a distinction should be made between the primary and secondary influencing factors for a particular cohesive powder mixture.

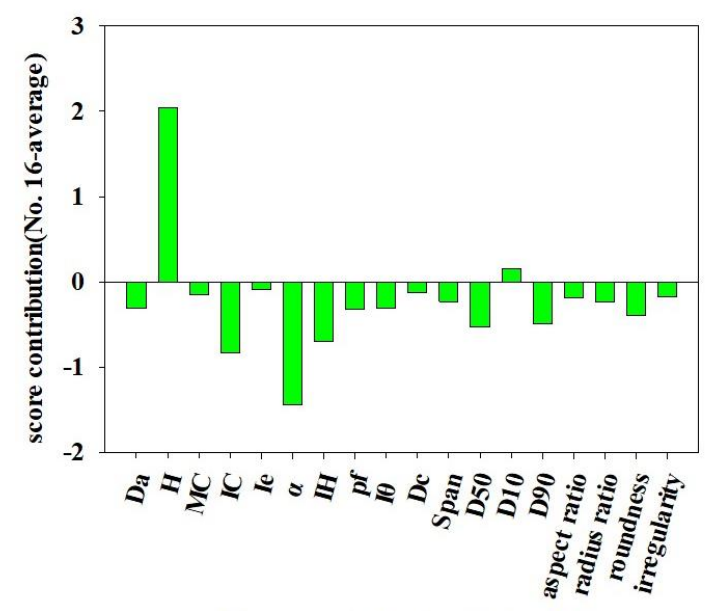

a. Taraxaci Herba (No. 16)

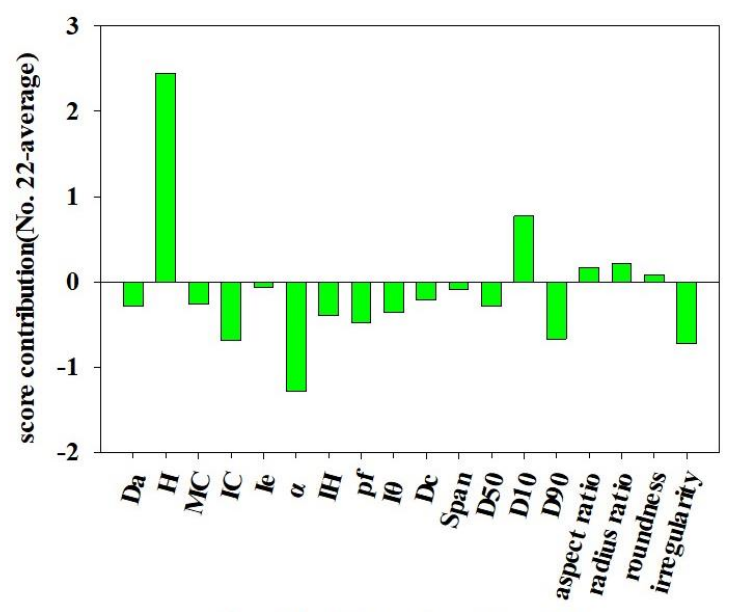

b. Cirsii Herba (No.22)

Figure 11. The contribution plots for Taraxaci Herba (No. 16) and Cirsii Herba (No. 22).

\section{Conclusions}

In this paper, the blending process in the preparation of diverse natural product powders with typically cohesive characteristics was taken as the research object. The MEMS NIR sensor combined with the modified adaptive modeling algorithm was successfully used to detect the blending homogeneity of cohesive powders during their industrial production. Compared with the previous fixed mixing time during the production, the online MEMS NIR spectroscopy technique can significantly reduce mixing time, improve mixing efficiency, and save production costs.

The innovation of this work is that it investigates the critical material attributes affecting the mixing time by developing an empirical relationship. It was found that the particle shape and powder flowability descriptors play a significant role in mixing cohesive powders. Thereby, decreasing the difference of flowability or particle shape between powders would be beneficial in improving blending processability. In future studies, more materials could be used to verify the accuracy of the empirical model, and numerical simulation studies could be conducted to understand the mixing mechanism of cohesive powders. Additionally, this paper provided a reference for other types of miniaturized NIR spectrometer to be applied in the pharmaceutical blending process.

Supplementary Materials: The following are available online at http://www.mdpi.com/2227-9717/7/9/568/s1.

Author Contributions: Conceptualization, B.X. and Y.Q.; formal analysis, G.S.; funding acquisition, B.X.; investigation, C.Y. and S.D.; project administration, X.S. and Y.Q.; resources, Z.Z. and J.F.; software, B.X. and Z.L.; validation, G.S., C.Y. and S.D.; writing—original draft, G.S.; writing—review \& editing, B.X.

Acknowledgments: The authors are thankful to the Scientific Research Program of Beijing University of Chinese Medicine (No. 2019-JYB-JS-015), the funding provided by Beijing Tcmages Pharmaceutical Co., Ltd., and the special project for Beijing Key Laboratory of TCM Manufacturing Process Control and Quality Evaluation supported by Beijing Municipal Science \& Technology Commission (No. Z151100001615065). 
Conflicts of Interest: The authors report no conflicts of interest. The authors alone are responsible for the content and writing of this article.

\section{References}

1. Scheibelhofer, O.; Balak, N.; Wahl, P.R.; Koller, D.M.; Glasser, B.J.; Khinast, J.G. Monitoring Blending of Pharmaceutical Powders with Multipoint NIR Spectroscopy. AAPS PharmSciTech 2013, 14, 234-244. [CrossRef] [PubMed]

2. Maesschalck, R.D.; Sànchez, F.C. On-Line Monitoring of Powder Blending with Near-Infrared Spectroscopy. Appl. Spectrosc. 1998, 52, 725-731. [CrossRef]

3. Hausman, D.S.; Cambron, R.T.; Sakr, A. Application of Raman spectroscopy for on-line monitoring of low dose blend uniformity. Int. J. Pharm. 2005, 298, 80-90. [CrossRef] [PubMed]

4. Florian-Algarin, M.; Méndez, R. Effect of material properties and design parameters on the final blend uniformity using experimental and simulation results. Powder Technol. 2015, 276, 156-165. [CrossRef]

5. Escotet-Espinoza, M.S.; Moghtadernejad, S.; Oka, S.; Wang, Y.; Roman-Ospino, A.; Schäfer, E.; Cappuyns, P.; Van Assche, I.; Futran, M.; Ierapetritou, M.; et al. Effect of tracer material properties on the residence time distribution (RTD) of continuous powder blending operations Part I of II: Experimental evaluation. Powder Technol. 2018, 342, 744-763. [CrossRef]

6. US Department of Health and Human Services, Food and Drug Administration. Guidance for Industry PAT-A Framework for Innovative Pharmaceutical Development, Manufacturing and Quality Assurance. 2004. Available online: http://www.fda.gov/downloads/Drugs/GuidanceComplianceRegulatoryInformation/ Guidances/ucm070305.pdf (accessed on 27 August 2019).

7. Shi, Z.; Mcghehey, K.C.; Leavesley, I.M.; Manley, L.F. On-line monitoring of blend uniformity in continuous drug product manufacturing process-The impact of powder flow rate and the choice of spectrometer: Dispersive vs. FT. J. Pharm. Biomed. Anal. 2016, 118, 259-266. [CrossRef] [PubMed]

8. Fonteyne, M.; Vercruysse, J.; De Leersnyder, F.; Besseling, R.; Gerich, A.; Oostra, W.; Remon, J.P.; Vervaet, C.; De Beer, T. Blend Uniformity Evaluation During Continuous Mixing in a Twin Screw Granulator by in-Line Nir Using a Moving F-Test. Anal. Chim. Acta 2016, 935, 213-223. [CrossRef] [PubMed]

9. Hattori, Y.; Otsuka, M. ATR/FT-IR and NIR Auto-correlation Spectroscopic Analysis of Powder Blending Uniformity of Low-content Magnesium Stearate and Potato Starch. Anal. Sci. Int. J. Jpn. Soc. Anal. Chem. 2017, 33, 65-68. [CrossRef]

10. Corredor, C.C.; Lozano, R.; Bu, X.; McCann, R.; Dougherty, J.; Stevens, T.; Both, D.; Shah, P. Analytical Method Quality by Design for an On-Line Near-Infrared Method to Monitor Blend Potency and Uniformity. J. Pharm. Innov. 2015, 10, 47-55. [CrossRef]

11. Wang, H.; Barona, D.; Oladepo, S.; Williams, L.; Hoe, S.; Lechuga-Ballesteros, D.; Vehring, R. Macro-Raman spectroscopy for bulk composition and homogeneity analysis of multi-component pharmaceutical powders. J. Pharm. Biomed. Anal. 2017, 141, 180-191. [CrossRef]

12. Ma, H.; Anderson, C. Characterization of pharmaceutical powder blends by NIR chemical imaging. J. Pharm. Sci. 2008, 97, 3305-3320. [CrossRef] [PubMed]

13. Osorio, J.G.; Stuessy, G.; Kemeny, G.J.; Muzzio, F.J. Characterization of pharmaceutical powder blends using in situ near-infrared chemical imaging. Chem. Eng. Sci. 2014, 108, 244-257. [CrossRef]

14. Uchiyama, J.; Aoki, S.; Uemoto, Y. New approach to evaluate the lubrication process in various granule filling levels and rotating mixer sizes using a thermal effusivity sensor. Chem. Pharm. Bull. (Tokyo) 2015, 63, 164-179. [CrossRef] [PubMed]

15. Roggo, Y.; Chalus, P.; Maurer, L.; Jent, N. A review of near infrared spectroscopy and chemometrics in pharmaceutical technologies. J. Pharm. Biomed. Anal. 2007, 44, 683-700. [CrossRef] [PubMed]

16. Tewari, J.; Strong, R.; Boulas, P. At-line determination of pharmaceuticals small molecule's blending end point using chemometric modeling combined with Fourier transform near infrared spectroscopy. Spectrochim. Acta A 2017, 17, 886-891. [CrossRef] [PubMed]

17. Momose, W.; Imai, K.; Yokota, S.; Yonemochi, E.; Terada, K. Process analytical technology applied for end-point detection of pharmaceutical blending by combining two calibration-free methods: Simultaneously monitoring specific near-infrared peak intensity and moving block standard deviation. Powder Technol. 2011, 210, 122-131. [CrossRef] 
18. Vanarase, A.U.; Järvinen, M.; Paaso, J.; Muzzio, F.J. Development of a methodology to estimate error in the on-line measurements of blend uniformity in a continuous powder mixing process. Powder Technol. 2013, 241, 263-271. [CrossRef]

19. Mukherjee, R.; Mao, C.; Chattoraj, S.; Chaudhuri, B. DEM based computational model to predict moisture induced cohesion in pharmaceutical powders. Int. J. Pharm. 2018, 536, 301-309. [CrossRef]

20. Deng, X.; Scicolone, J.V.; Davé, R.N. Discrete element method simulation of cohesive particles mixing under magnetically assisted impaction. Powder Technol. 2013, 243, 96-109. [CrossRef]

21. Binici, H.; Aksogan, O.; Cagatay, I.H.; Tokyay, M.; Emsen, E. The effect of particle size distribution on the properties of blended cements incorporating GGBFS and natural pozzolan (NP). Powder Technol. 2007, 177, 140-147. [CrossRef]

22. Pingali, K.C.; Shinbrot, T.; Hammond, S.V.; Muzzio, F.J. An observed correlation between flow and electrical properties of pharmaceutical blends. Powder Technol. 2009, 192, 157-165. [CrossRef]

23. Shenoy, P.; Viau, M.; Tammel, K.; Innings, F.; Fitzpatrick, J.; Ahrné, L. Effect of powder densities, particle size and shape on mixture quality of binary food powder mixtures. Powder Technol. 2015, 272, 165-172. [CrossRef]

24. Liew, C.V.; Karande, A.D.; Heng, P.W.S. In-line quantification of drug and excipients in cohesive powder blends by near infrared spectroscopy. Int. J. Pharm. 2010, 386, 138-148. [CrossRef]

25. Casian, T.; Iurian, S.; Gavan, A.; Revnic, C.; Porav, S.; Porfire, A.; Vlase, L.; Tomuță, I. Near Infra-Red spectroscopy for content uniformity of powder blends-Focus on calibration set development, orthogonality transfer and robustness testing. Talanta 2018, 188, 404-416. [CrossRef] [PubMed]

26. Lin, Y.; Li, W.; Xu, J.; Boulas, P. Development of a NIR-based blend uniformity method for a drug product containing multiple structurally similar actives by using the quality by design principles. Int. J. Pharm. 2015, 488, 120-126. [CrossRef] [PubMed]

27. Besseling, R.; Damen, M.; Tran, T.; Nguyen, T.; Dries, K.V.D.; Oostra, W.; Gerich, A. An efficient, maintenance free and approved method for spectroscopic control and monitoring of blend uniformity: The moving F-test. J. Pharm. Biomed. Anal. 2015, 114, 471-481. [CrossRef]

28. Sibik, J.; Chalus, P.; Maurer, L.; Murthy, A.; Krimmer, S. Mechanistic approach in powder blending PAT: Bi-layer mixing and asymptotic end point prediction. Powder Technol. 2017, 308, 306-317. [CrossRef]

29. Flåten, G.R.; Belchamber, R.; Collins, M.; Walmsley, A.D. Caterpillar-An adaptive algorithm for detecting process changes from acoustic emission signals. Anal. Chim. Acta 2005, 544, 280-291. [CrossRef]

30. Flåten, G.R.; Ferreira, A.P.; Bellamy, L.; Frake, P. PAT within the QbD Framework: Real-Time End Point Detection for Powder Blends in a Compliant Environment. J. Pharm. Innov. 2012, 7, 38-45. [CrossRef]

31. Geldart, D. Types of gas fluidization. Powder Technol. 1973, 7, 285-292. [CrossRef]

32. Capece, M.; Huang, Z.; To, D.; Aloia, M.; Muchira, C.; Dave, R.; Yu, A. Prediction of porosity from particle scale interactions: Surface modification of fine cohesive powders. Powder Technol. 2014, 254, 103-113. [CrossRef]

33. Wu, H.; White, M.; Khan, M. An Integrated Process Analytical Technology (PAT) Approach for Process Dynamics-Related Measurement Error Evaluation and Process Design Space Development of a Pharmaceutical Powder Blending Bed. Org. Process Res. Dev. 2015, 19, 215-226. [CrossRef]

34. Osorio, J.G.; Stuessy, G.; Kemeny, G.J.; Muzzio, F.J. Micro-mixing dynamics of active pharmaceutical ingredients in bin-blending. Chem. Eng. Process. 2016, 102, 141-155. [CrossRef]

35. Kirchler, C.G.; Pezzei, C.K.; Beć, K.B.; Mayr, S.; Ozaki, Y.; Huck, C.W.; Ishigaki, M. Critical evaluation of spectral information of benchtop vs. portable near-infrared spectrometers: Quantum chemistry and two-dimensional correlation spectroscopy for a better understanding of PLS regression models of the rosmarinic acid content in Rosmarini folium. Analyst 2017, 142, 455-464. [CrossRef]

36. Peter, J.; Brush, A.; Alexander, W. Using MEMS to Control Blending at AstraZeneca. 2006. Available online: https://www.pharmamanufacturing.com/articles/2006/149/ (accessed on 21 August 2006).

37. Chen, Y.; Yang, J.; Dave, R.N.; Pfeffer, R. Fluidization of coated group C powders. AIChE J. 2010, 54, $104-121$. [CrossRef]

38. Shi, W.; Galella, E.; Sprockel, O. Macro-and micro-mixing of a cohesive pharmaceutical powder during scale up. Powder Technol. 2015, 274, 319-323. [CrossRef]

39. Mangal, S.; Gengenbach, T.; Millington-Smith, D.; Armstrong, B.; Morton, D.A.; Larson, I. Relationship between the cohesion of guest particles on the flow behaviour of interactive mixtures. Eur. J. Pharm. Biopharm. 2016, 102, 168-177. [CrossRef] 
40. Xu, B.; Lin, Z.; Wu, Z.; Shi, X.; Qiao, Y.; Luo, G. Target-oriented Overall Process Optimization (TOPO) for Reducing Variability in the Quality of Herbal Medicine Products. Chemom. Intell. Lab. Syst. 2013, 128, 144-152. [CrossRef]

41. Xiong, H.; Lawrence, X.Y.; Qu, H. Batch-to-batch quality consistency evaluation of botanical drug products using multivariate statistical analysis of the chromatographic fingerprint. AAPS PharmSciTech 2013, 14, 802-810. [CrossRef]

42. Dai, S.; Xu, B.; Shi, G.; Liu, J.; Zhang, Z.; Shi, X.; Qiao, Y. SeDeM expert system for directly compressed tablet formulation: A review and new perspectives. Powder Technol. 2019, 342, 517-527. [CrossRef]

43. Jys, T.; Liew, C.V.; Pws, H. Powder Flow Testing: Judicious Choice of Test Methods. AAPS PharmSciTech 2017, 18, 1843-1854. [CrossRef]

44. Geldart, D.; Harnby, N.; Wong, A.C. Fluidization of cohesive powders. Powder Technol. 1984, 37, $25-37$. [CrossRef]

45. Capece, M.; Ho, R.; Strong, J.; Gao, P. Prediction of powder flow performance using a multi-component granular Bond number. Powder Technol. 2015, 286, 561-571. [CrossRef]

46. Capece, M.; Silva, K.R.; Sunkara, D.; Strong, J.; Gao, P. On the Relationship of Inter-particle Cohesiveness and Bulk Powder Behavior: Flowability of Pharmaceutical Powders. Int. J. Pharm. 2016, 511, 178-189. [CrossRef]

47. Legoix, L.; Gatumel, C.; Milhe, M.; Berthiaux, H. Rheology of cohesive powders in a pilot scale planetary blender. Powder Technol. 2017, 305, 609-619. [CrossRef]

48. Van Snick, B.; Dhondt, J.; Pandelaere, K.; Bertels, J.; Mertens, R.; Klingeleers, D.; Di Pretoro, G.; Remon, J.P.; Vervaet, C.; De Beer, T.; et al. A multivariate raw material property database to facilitate drug product development and enable in-silico design of pharmaceutical dry powder processes. Int. J. Pharm. 2018, 549, 415-435. [CrossRef]

49. Schiller, M.; Von Der Heydt, H.; März, F.; Schmidt, P.C. Quantification of sugars and organic acids in hygroscopic pharmaceutical herbal dry extracts. J. Chromatogr. A 2002, 968, 101-111. [CrossRef]

50. Igne, B.; Talwar, S.; Drennen, J.K.; Anderson, C.A. Online Monitoring of Pharmaceutical Materials Using Multiple NIR Sensors-Part II: Blend End-point Determination. J. Pharm. Innov. 2013, 8, 45-55. [CrossRef]

51. Zhou, Z.; Li, J.; Zhou, J.; Li, S.; Feng, J. Enhancing mixing of cohesive particles by baffles in a rotary drum. Particuology 2016, 25, 104-110. [CrossRef]

52. Fu, X.; Huck, D.; Makein, L.; Armstrong, B.; Willen, U.; Freeman, T. Effect of particle shape and size on flow properties of lactose powders. Particuology 2012, 10, 203-208. [CrossRef]

53. Abhaykumar, B. Correlation between Physical Properties and Flowability Indicators for Fine Powders. Master's Thesis, Department of Chemical Engineering, University of Saskatchewan, Saskatoon, SK, Canada, 2006.

54. Juarez-Enriquez, E.; Olivas, G.I.; Zamudio-Flores, P.B.; Ortega-Rivas, E.; Perez-Vega, S.; Sepulveda, D.R. Effect of water content on the flowability of hygroscopic powders. Int. Food Eng. 2017, 205, 12-17. [CrossRef] 